\title{
An Exceptionally Preserved Specimen From the Green River Formation Elucidates Complex Phenotypic Evolution in Gruiformes and Charadriiformes
}

\author{
Grace Musser* and Julia A. Clarke \\ Department of Geological Sciences, The University of Texas at Austin, Austin, TX, United States
}

\section{OPEN ACCESS}

Edited by:

Daniel J. Field,

University of Cambridge,

United Kingdom

Reviewed by:

Gerald Mayr,

Senckenberg Museum, Germany

Junya Watanabe

University of Cambridge,

United Kingdom

*Correspondence:

Grace Musser

gmusser@utexas.edu

Specialty section:

This article was submitted to

Paleontology,

a section of the journal

Frontiers in Ecology and Evolution

Received: 07 May 2020 Accepted: 09 September 2020

Published: 26 October 2020

Citation:

Musser G and Clarke JA (2020) An Exceptionally Preserved Specimen

From the Green River Formation

Elucidates Complex Phenotypic

Evolution in Gruiformes

and Charadriiformes.

Front. Ecol. Evol. 8:559929.

doi: 10.3389/fevo.2020.559929
The stem lineage relationships and early phenotypic evolution of Charadriformes (shorebirds) and Gruiformes (rails, cranes, and allies) remain unresolved. It is still debated whether these clades are sister-taxa. New phylogenetic analyses incorporating Paleogene fossils have the potential to reveal the evolutionary connections of these two speciose and evolutionarily critical neoavian subclades. Although Gruiformes have a rich Paleogene fossil record, most of these fossils have not been robustly placed. The Paleogene fossil record of Charadrifformes is scarce and largely consists of fragmentary single elements. Only one proposed Eocene charadriiform-like taxon, Scandiavis mikkelseni of Denmark, is represented by a partial skeleton. Here, we describe a new species from the early Eocene Green River Formation of North America comprising a partial skeleton and feather remains. Because the skeleton lacks the pectoral girdle and forelimbs as in S. mikkelseni, only features of the skull, axial skeleton, and hind limb are available to resolve the phylogenetic placement of this taxon. These anatomical subregions initially showed features seen in Charadriiformes and Gruiformes. To assess placement of this taxon, we use a matrix consisting of 693 morphological characters and 60 taxa, including S. mikkelseni and the oldest known charadriiform taxa represented by single elements. These more fragmentary records comprise two distal humeri from the earliest Eocene Naranbulag Formation of Mongolia and the early Eocene Nanjemoy Formation of Virginia. Our phylogenetic analyses recover the new taxon and S. mikkelseni alternatively as a charadriiform or as a stem-gruiform; placement is contingent upon enforced relationships for major neoavian subclades recovered by recent molecular-based phylogenies. Specifically, when constraint trees based on results that do not recover Charadriiformes and Gruiformes as sister-taxa are used, the new taxon and S. mikkelseni are recovered within stem Gruiformes. Both Paleogene fossil humeri are consistently recovered within crown Charadriiformes. If placement of these humeri or the new taxon as charadriforms are correct, this may indicate that recent divergence time analyses have underestimated the crown age of another major crown avian subclade; however, more complete sampling of these taxa is necessary, especially of more complete specimens with pectoral elements.

Keywords: avian phylogeny, Neoaves, Eocene, feathers, fossil, divergence time estimation, morphology 


\section{INTRODUCTION}

Although there is a growing consensus around the majority of relationships among avian subclades, positions of several subclades have been persistently debated. Charadriiformes (shorebirds) and Gruiformes (rails, cranes, and allies) have both been described as some of the most speciose and phylogenetically enigmatic clades of birds (Livezey, 1998, 2010; Mayr, 2011b). Understanding evolution in both clades is critical to resolving the stem lineage relationships of Neoaves, a group that contains approximately $95 \%$ of all living bird species, and to elucidating phenotypic evolution across basal Neoaves. There is a lack of consensus among large-scale phylogenetic studies of Neoaves concerning the relationships of, and early phenotypic evolution in, Charadriiformes or Gruiformes. A Charadriiformes + Gruiformes clade was recovered using a variety of datatypes and analytical approaches including recent large genome-based datasets (e.g., Cracraft, 1988; van Tuinen and Hedges, 2001; Livezey and Zusi, 2007; Bertelli et al., 2011; Jarvis et al., 2014; Musser and Cracraft, 2019, primary analysis of Kimball et al., 2019). However, it is not recovered in other large molecular datasets (Hackett et al., 2008; Prum et al., 2015; Reddy et al., 2017, additional analyses of Kimball et al., 2019).

Assessment of Paleogene fossils can directly inform the timing of key divergences in Neoaves. Although Gruiformes have a rich Paleogene fossil record, these fossils have not been robustly placed despite several attempts to do so across large-scale morphological analyses (Livezey and Zusi, 2007; Mayr, 2009, 2017; Musser and Cracraft, 2019; Musser et al., 2019). Even the Messelornithidae, the most complete and wellpreserved Paleogene rail-like fossils that are represented by over 500 specimens (Mayr, 2017), are of debated affinities (Musser et al., 2019). The Paleogene fossil record of Charadriiformes is conversely scarce and largely consists of fragmentary single elements. The only previously proposed Paleogene charadriiform represented by a partial skeleton is Scandiavis mikkelseni (Bertelli et al., 2013) of the earliest Eocene marine Fur Formation of Denmark ( $54 \mathrm{Ma}$, Bertelli et al., 2011). S. mikkelseni is missing the shoulder girdle, forelimbs and sternum but is exceptionally preserved in three dimensions. Despite its preservation, this specimen could not be confidently assigned to Charadriiformes (Bertelli et al., 2013). The oldest-known unambiguous charadriiform fossils are represented by single elements and comprise distal humeri from the earliest Eocene lacustrine Naranbulag Formation of Mongolia ( $55 \mathrm{Ma}$, Hood et al., 2019) and the early Eocene marine Nanjemoy Formation of Virginia (53.6-52.8 Ma, Mayr, 2016). All other charadriiform fossils postdate these specimens, with most being younger than Eocene in age (Smith, 2015; Mayr, 2017). Stem representatives of Alcidae from the late Eocene and Turnicidae and Jacanidae from the early Oligocene remain the earliest charadriiform birds that can be confidently assigned to extant lineages (Mayr, 2011b; Smith, 2015). While the stem turnicids Turnipax and Cerestenia are represented by partial skeletons (Mayr, 2000b), the jacanid remains are fragmentary (Olson, 1976; Rasmussen et al., 1987), leaving phenotypic evolution at the base of Charadriiformes to remain largely unknown.
Here, we describe a two-dimensionally preserved partial skeleton of a bird from the early Eocene Fossil Butte Member (FBM; $51.97 \pm 0.16 \mathrm{Ma}$, Smith et al., 2010) of the lacustrine Green River Formation of North America with exquisitely preserved plumage. Grande (2013) preliminarily reported that this taxon could be related to the extinct Salmila robusta (Mayr, 2000a). It was considered to be possibly flightless due to having what appeared to be small wing feathers (Grande, 2013); however, the sternum, shoulder girdle and forelimbs are missing along with their associated feathers. Salmila robusta is a slightly larger taxon of the middle Eocene Messel Formation in Hessen, Germany (Mayr, 2000a). S. robusta was originally placed within Cariamae (Seriemas; Mayr, 2000a) and later assigned to its own family (Salmilidae) as the sister-taxon of Cariamae (Mayr, 2002; with Cariamae including Idiornis, Psilopterus, Phorusrhacos, and Cariama in this study) after identification of an additional specimen and phylogenetic analysis. Three total specimens of $S$. robusta have been identified (Mayr, 2000a, 2002). S. robusta has also been thought to share some similarities with Psophia (trumpeters), especially within the tarsometatarsus (Mayr, 2000a). No cariamid, gruoid (crane, limpkin, or trumpeter-like) or charadriiform birds have been described from the Green River Formation (Grande, 2013).

We identify this fossil as the holotype specimen of a new species. New x-ray computed tomography (CT) images allowed us to recover previously hidden morphologies, revealing it to represent a bird from rarely sampled environments of Fossil Lake (Grande, 2013) and to represent a new clade for the Green River Formation. The specimen was found at the mid-lake locality, locality A (Grande and Buchheim, 1994; Grande, 2013), and is one of only two avian skeletons published from this site (the other is that of a coliform or mousebird; Ksepka and Clarke, 2010a). Additional avian remains recovered from Locality A comprise two feathers, one of which may be from the giant Gastornis (Grande, 2013). Aquatic birds (e.g., frigatebirds, presbyornithids) are among the most common avian species found in the FBM as well as an array of disparate terrestrial taxa including rail-like birds (messelornithids), paleognathous birds (lithornithids), stem parrots and roller-like birds (primobucconids; Grande, 1984; Hesse, 1992; Ericson, 1997, 1999, 2000; Olson and Matsuoka, 2005; Clarke et al., 2009; Ksepka and Clarke, 2010b, 2012; Weidig, 2010; Ksepka et al., 2011; Grande, 2013; Smith, 2013; Nesbitt and Clarke, 2016). Character analysis and phylogenetic placement of this specimen (FMNH PA778) allows new insight into outstanding issues of phenotypic evolution and divergence timing as well as new perspectives on paleoenvironmental and biogeographic history in Neoaves.

\section{INSTITUTIONAL ABBREVIATIONS}

AMNH, American Museum of Natural History, New York, NY, United States; FMNH, Field Museum of Natural History, Chicago, IL, United States; HLMD, Hessisches Landesmuseum Darmstadt, Germany; M, the Texas Memorial Museum, 
Austin, TX, United States.; USNM, National Museum of Natural History, Smithsonian Institution, Washington, DC, United States. Specimen numbers are presented in Table 1.

\section{SYSTEMATIC PALEONTOLOGY}

AVES (Linnaeus, 1758), NEOGNATHAE (Pycraft, 1900), Neoaves (Sibley et al., 1988), Nahmavis grandei, gen. et sp. nov.

\section{Holotype Specimen}

FMNH PA778, a partial skeleton with feathers and tracheal rings preserved within a kerogen-rich laminated micrite slab.
Remains of the sternum, pectoral girdle and forelimb are absent (Figures 1,3). Measurements are provided in Table 2.

\section{Etymology}

Nahmavis is Native American in origin (Nahma, used by the Shoshoni Great Basin tribe indigenous to this region) and means "together" or "of two things" (Shoshoni Language Project, 2018). The name references the combination of features in this new taxon. The species honors Dr. Lance Grande, who collected the holotype specimen, in recognition of his premier and extensive research on the Green River Formation.

\section{Type Locality and Horizon}

The holotype specimen was collected from Fossil Butte Member (sensu Buchheim, 1994) Locality A (F-1 A in Grande and Buchheim, 1994; Grande, 2013), located in SE1/4, SE1/4, Sec. 19,

TABLE 1 | Specimen numbers of newly added taxa and skeletal specimens used for comparison during fossil description and phylogenetic analyses.

\begin{tabular}{|c|c|}
\hline Group Name & Species Sampled and Specimen Numbers \\
\hline Tinamiformes & Crypturellus undulatus (AMNH 2751, AMNH 6479), Tinamus solitarius (AMNH 21983, USNM 561269, USNM 345133) \\
\hline Galliformes & Lophura bulweri (AMNH 10962, AMNH 16532), Gallus gallus (AMNH 18555, AMNH 4031, M-12244, USNM 489422) \\
\hline Anseriformes & $\begin{array}{l}\text { Chauna torquata (M-10449, USNM 646637), Anas platyrhynchos (USNM 633396, USNM 610643), Mergus serrator (USNM 490105, } \\
\text { USNM 634853, USNM 430710) }\end{array}$ \\
\hline Gaviiformes & Gavia immer (AMNH 15919, USNM 501589) \\
\hline Sphenisciiformes & Spheniscus humboldti (AMNH 4921) \\
\hline Phoenicopteriformes & Phoenicopterus chilensis (M-4923, M-5325) \\
\hline Podicipediformes & Podiceps cristatus (AMNH 25241, USNM 502553, USNM 560595) \\
\hline Caprimulgiformes & Caprimulgus carolinensis (USNM 559607) \\
\hline Otidiformes & Chlamydotis macqueenii (USNM 430378, USNM 430485, AMNH 28665) \\
\hline Columbiformes & Columba livia (USNM 555707) \\
\hline Opisthicomiformes & Opisthocomus hoazin (AMNH 12127, AMNH 24230, USNM 612024, USNM 344066, USNM 344065) \\
\hline Charadriiformes & $\begin{array}{l}\text { Eudromias ruficollis (AMNH 7013, USNM 322963, USNM 322962), Jacana jacana (FMNH 376137, USNM 560148, USNM 614605, USNM } \\
\text { 345812), Haematopus ostralegus (FMNH 338440, USNM 502440, USNM 560934, AMNH 1681), Burhinus bistriatus (AMNH 2630, FMNH } \\
\text { 289831, USNM 621089, USNM 626233, USNM 432021), Charadrius semipalmatus (AMNH 9963, FMNH 342530, USNM 489728, USNM } \\
\text { 489665, USNM 489599), Vanellus coronatus (USNM 636688, USNM 636689, AMNH 5243), Chionis alba (AMNH 549, AMNH 879, USNM } \\
\text { 553253, USNM 490989), Pluvianus aegyptius (FMNH 93449, FMNH 291228, USNM 491870, USNM 500294), Larus atricilla (M-10469, } \\
\text { USNM 560290, USNM 227064), Recurvirostra avosetta (USNM 556295, USNM 610452, AMNH 28666), Stercorarius longicaudus (USNM } \\
\text { 491644, USNM 491643, AMNH 21036), Thinocorus rumicivorous (USNM 227504, USNM 491022, AMNH 10143), Turnix nigricollis (USNM } \\
\text { 488643, USNM 432224, AMNH 1994, AMNH 5381) }\end{array}$ \\
\hline
\end{tabular}

Gruiformes Psophia crepitans (AMNH 29322, FMNH 338504, USNM 621709, USNM 429974), Aramus guarauna (AMNH 24194, NC State 18405, FMNH 376076, USNM 612025, USNM 226809), Balearica regulorum (AMNH 10699, USNM 637581, USNM 647263, USNM 631784), Grus japonensis (AMNH 1938, AMNH 1718, AMNH 4252), Podica senegalensis (AMNH 4148, AMNH 4208, AMNH 5268, USNM 562803), Heliornis fulica (FMNH 376129, USNM 623068, USNM 19159, USNM 345807, USNM 321493, YPM 109145), Heliopais personata (USNM 534558, USNM 344532), Sarothrura lugens (AMNH 2417, AMNH 4235), Sarothrura pulchra (FMNH 490196, USNM 291778, USNM 292395, AMNH 4235), Himantornis haematopus (AMNH 4183, UNSM 318391), Habroptila wallacii (USNM 560793, USNM 557026, USNM 557027, USNM 572365, USNM 560792, USNM 557025), Gallicrex cinerea (USNM 319118, USNM 319481, USNM 489266, USNM 292017), Canirallus oceleus batesi (AMNH 4151), Aramides cajanea (AMNH 4343, AMNH 8637, FMNH 105856, USNM 612270*, USNM 612266), Rallus longirostris (M-10359, USNM 499648, USNM), Gallinula chloropus (AMNH 28451, FMNH 105107, USNM 499259), Porphyrula martinica (USNM 611560, USNM 611561)

Phaethontiformes Phaethon aethereus (AMNH 28494, FMNH 348136, FMNH 339435, USNM 558044, USNM 525793)

Eurypygiformes Eurypyga helias (AMNH 3750, AMNH 4293, FMNH 376130, FMNH 106439, USNM 637209, USNM 623251, USNM 344047), Rhynochetos jubatus (AMNH 1326, AMNH 554, FMNH 291228, USNM 612087, USNM 018994)

Cariamiformes Cariama cristata (AMNH 1722, AMNH 8667, AMNH 8646, M-10446, FMNH 105634, USNM 555731, USNM 430173, USNM 631176), Chunga burmeisteri (USNM 431487, AMNH 4250)

Accipitriformes Leptosomiformes Cathartes burrovianus (AMNH 1264, USNM 623071) Extinct Taxa Leptosomus discolor (AMNH 10083, USNM 291844, USNM 291845) Nahmavis grandei (FMNH PA778), Scandiavis mikkelseni (Bertelli et al., 2013), Salmila robusta (Mayr, 2000a, 2002), Pellornis mikkelseni (MGUH 29278, DK664, FUM 1681a; Bertelli et al., 2011; Musser et al., 2019), Songzia acutunguis (Wang et al., 2012), Messelornis cristata (USNM 462392, Hesse, 1990; Bertelli et al., 2011) 


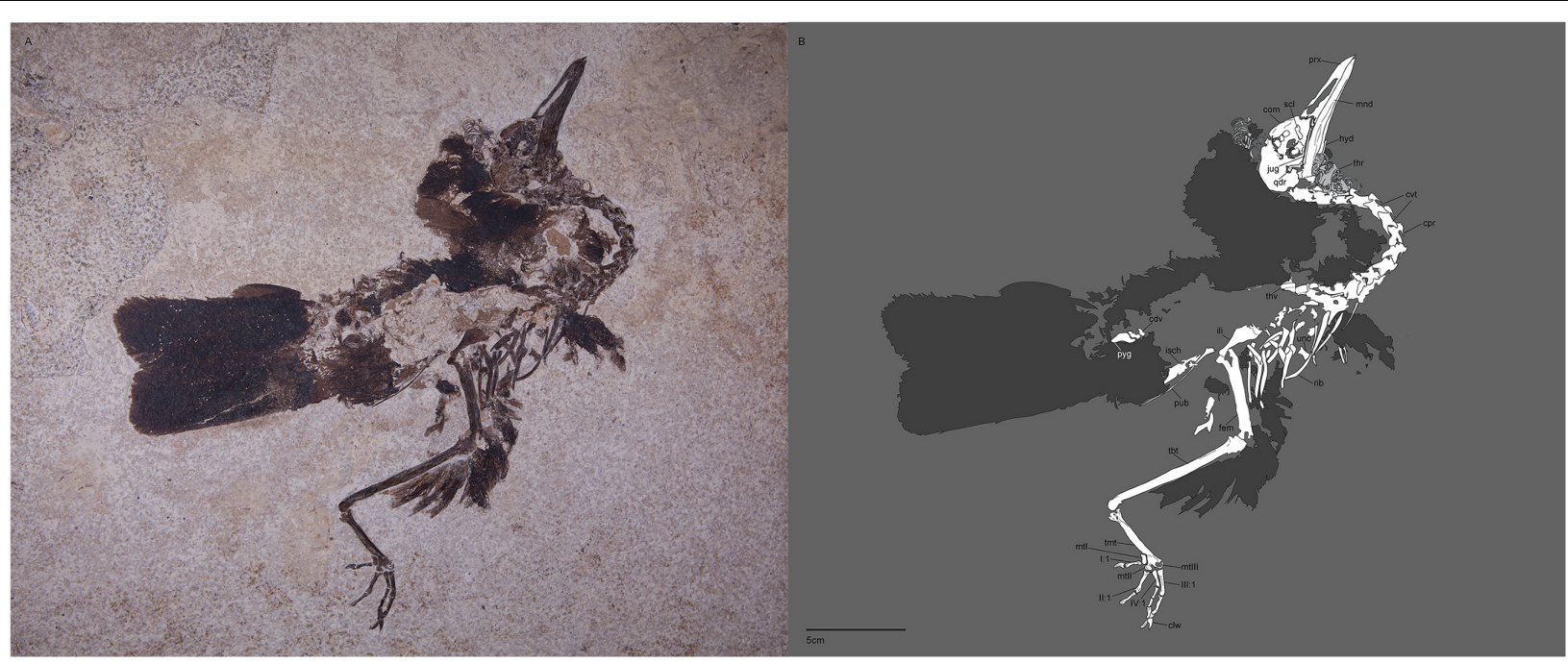

FIGURE 1 | Photograph (A) and line drawing (B) of FMNH PA778. Bone is unfilled, matrix is gray, cartilaginous tracheal and possible syringeal rings are shown in light gray, and feathers and other unidentifiable soft tissue is displayed in dark gray. Extremely crushed bone and bone margin is delimited with dashed margins. Anatomical abbreviations: prx, premaxilla; com, crest-like orbital margin; scl, scleral rings; qdr, quadrate; mnd, mandible; jug, jugal; hyd hyoid; cvt, cervical vertebrae; cpr, costal processes; thv, thoracic vertebra; cdv, caudal vertebra; pub, pubis; pyg, pygostyle; rib, ribs; unc, uncinate process; ili, preacetabular ilium; isch, postacetabular ischium; pub, pubis; fem, femur; tbt, tibiotarsus; tmt, tarsometatarsus; mtIl, trochlea metatarsal II; mtIII, trochlea metatarsal III; mtl, metatarsal I; I:1, hallux; II:1, phalanx one of digit II; III:1, phalanx one of digit III; IV:1, phalanx one of digit IV; clw, claw; thr, tracheal rings.

TABLE 2 | Selected measurements of Nahmavis grandei in millimeters (mm), taken from surface of slab (does not include CT scan measurements; left/right) compared with previously published measurements of Salmila robusta and Scandiavis mikkelseni.

\begin{tabular}{|c|c|c|c|}
\hline Measurement (mm) & N. grandei FMNH PA778 & S. robusta SMF-ME 3014 Mayr, 2000a & S. mikkelseni FU171x (Bertelli et al., 2013) \\
\hline Total skull length & 67.8 & & 49.5 \\
\hline Rostrum length & 35.1 & & \\
\hline Quadrate visible height & /6.5 & & \\
\hline Femur length & $/ 41.0$ & $/ \sim 45$ & /33.2 \\
\hline Tibiotarsus length & $/ 60.9$ & $69.7 / 64.4$ & $47.7 /$ \\
\hline Tarsometatarsus length & /32.0 & $42.9 / 44.7$ & $25.5 / 25.4$ \\
\hline I:1 length & /6.6 & 7.6 & \\
\hline I:2 length & /4.9 & 5.0 & \\
\hline II:1 length & $/ 10.0$ & 11.8 & \\
\hline II:2 length & /8.5 & 8.2 & \\
\hline III:1 length & $/ 11.4$ & 11.2 & \\
\hline III:2 length & $/ 8.9$ & 9.3 & \\
\hline III:3 length & /8.1 & 8.4 & \\
\hline N:1 length & /8.1 & 7.6 & \\
\hline N:2 length & $/ 5.10$ & 4.2 & \\
\hline N:3 length & $/ 4.80$ & 4.2 & \\
\hline N:4 length & $/ 4.80$ & 5.1 & \\
\hline IV:5 length & $/ 4.80$ & 5.6 & \\
\hline
\end{tabular}

Pedal phalanges are described using the format (digit:phalanx). Measurements are given for holotype specimens only.

T.21N., R.117W., and NE1/4, NE1/4, Sec. 30, T.21N., R117W., Kemmerer 15 min Quadrangle (USGS). FBM Locality A is a mid-lake locality and is within a $30-40 \mathrm{~cm}$ thick horizon representing roughly a few 100 years of the early Eocene (Grande and Buchheim, 1994). The mid-lake fossil-bearing, laminated micrite facies are made up of thin calcite laminae that alternate with almost pure kerogen (Grande and Buchheim, 1994). Few other bird skeletons have been recovered from the mid-lake locality, with the majority being recovered from the near-shore deposits of FBM locality $\mathrm{H}$ (F-2 A in Grande and Buchheim, 1994; Grande, 2013). The mid-lake locality is additionally characterized by a sharp decrease in benthic fauna, perhaps suggesting that bottom conditions were primarily anoxic or dysaerobic as in the avian fossil-bearing deposits of the Fur Formation (Pedersen and Surlyk, 1983; Bertelli et al., 2010). 


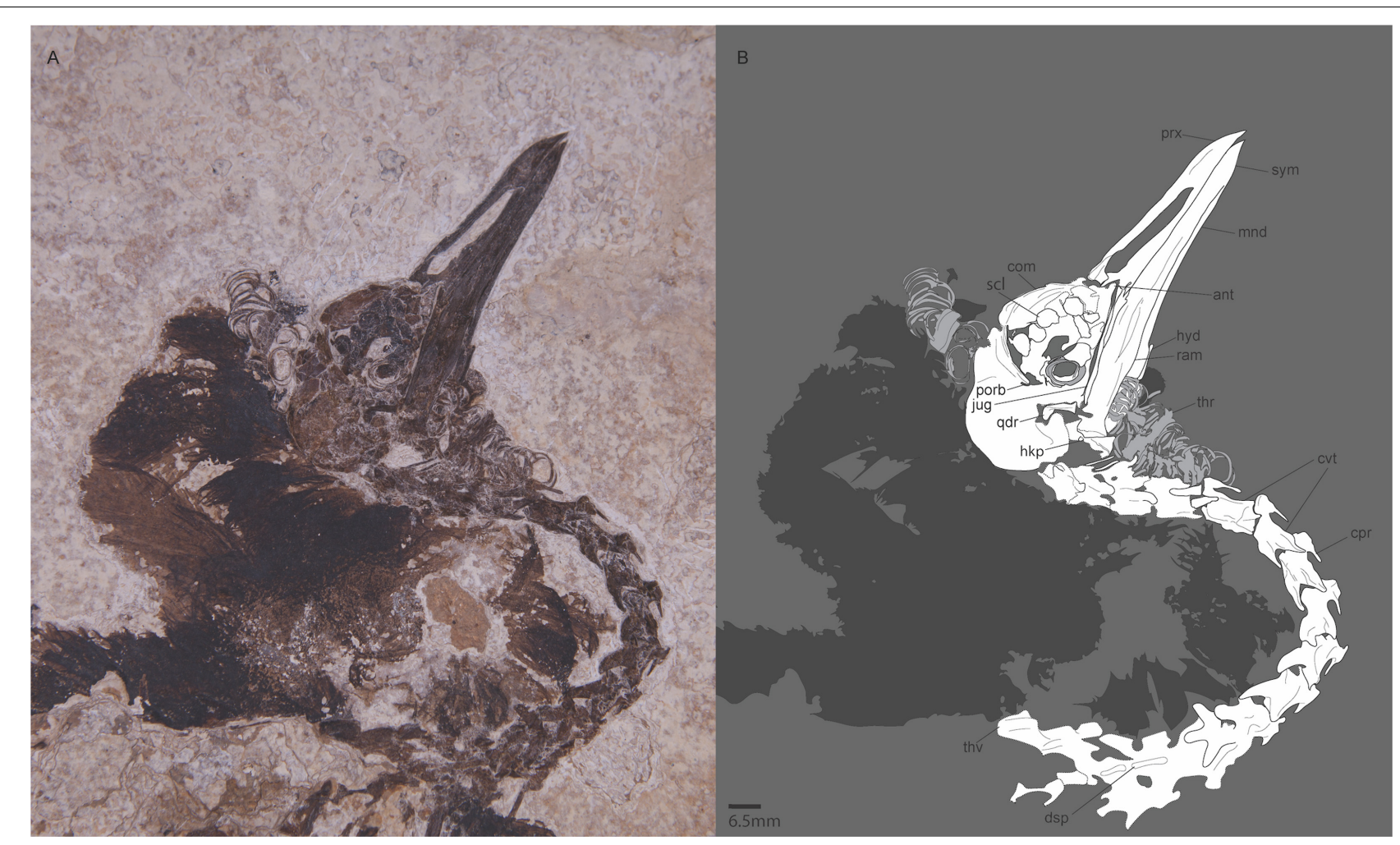

FIGURE 2 | Photograph (A) and line drawing (B) of the head and neck of FMNH PA778. Bone is unfilled, matrix is gray, cartilaginous tracheal and possible syringeal rings are shown in light gray, and feathers and other unidentifiable soft tissue is displayed in dark gray. Extremely crushed bone and bone margin is delimited with dashed margins. Anatomical abbreviations: prx, premaxilla; com, crest-like orbital margin; ant, antorbital angle; scl, scleral rings; porb, postorbital process; qdr, quadrate; mnd, mandible; hkp, hook-like process; ram, mandibular ramus; sym, symphysis; jug, jugal; hyd, hyoid; cvt, cervical vertebrae; cpr, costal processes; thv, thoracic vertebra; dsp, dorsal spinous process; thr, tracheal rings.

\section{Diagnosis}

Nahmavis grandei is diagnosed by a proposed unique combination of characters comprising (1) holorhinal nares rostral to the zona flexoria craniofacialis (Figures 1, 2, 6A), (2) a prominent, dorsally protruding crest-like orbital margin (Figures 1, 2, com; see Musser and Cracraft, 2019), (3) a quadrate with apneumatic, well-separated heads (Figures 2, 3A-C, 6D,E), (4) a quadrate with a prominent crista lateralis (Figures 3B,C,L, 6E), (5) a prominent crista tympanica of the quadrate that terminates ventrally within the ventral half of the otic process (Figures 3A,C, ct), (6) a caudally concave otic process of the quadrate (Figures 3C, 6D), (7) a caudal condyle that is confluent with the lateral condyle (Figures 3C,L, 6D), (8) absence of a notarium (Figure 1), (9) preacetabular ilia that are unfused to the synsacrum (Figure 1, ili and Figure 6H), (10) an elongate, thin and recurved pubis (Figure 1, pub) (11) a femur that is over half the length of the tibiotarsus (Figure 1, fem), (12) a prominent crista cnemialis cranialis of the tibiotarsus that is proximally projected above the fossa retropatellares (Figure 3E, ccc), (13) a tarsometatarsus that approximately half the length of the tibiotarsus (Figure 1, tmt), (14) a medial hypotarsal crest that is projected farther plantar than the lateral crest (Figures $\mathbf{3}$ - $-\mathbf{L}$, crm), (15) a deep sulcus extensorius of the tarsometatarsus (Figures 3J,K, ext), (16) plantar alae present on metatarsal trochleae IV and II (Figures 3J-L), (17) an unbowed pedal digit I: phalanx 1 that is about half the length of pedal digit III:1 (Figures 3J-L, I:1), (18) a lack of a plantomedial flange on proximal margin of pedal digit IV:1 (Figures 3J-L), and (19) a pedal digit IV:4 that is more elongate than pedal digit IV:3 (Figure 3L). Diagnosis for the genus as per the species.

\section{Differential Diagnosis}

Nahmavis grandei can be distinguished from earliest Eocene Scandiavis mikkelseni Bertelli et al. (2013) due to possessing (1) less rostrocaudally and dorsoventrally extensive nares (Figures 1, 2), (2) a more acute antorbital angle of approximately $45^{\circ}$ (Figure 2, ant), (3) a more caudally elongated cranium (Figures 1, 2), (4) a ventrally oriented postorbital process (Figure 2, porb), (5) a less cranially projected crista cnemialis cranialis of the tibiotarsus (Figures 3D,E, ccc), (6) a crista cnemialis cranialis with a more acuminate distal apex than that of S. mikkelseni (Figures 3D,E; apx), (7) a lack of a notch along the distal rim of the medial condyle of the tibiotarsus (Figures 3G,H), (8) a deeper fossa parahypotarsalis lateralis in the tarsometatarsus (Figure 3L, phl), and (9) a longer femur and tibiotarsus (Figure 1, fem and tbt; Table 2). N. grandei is differentiated from the charadriiform-like Morsoravis sedilis Bertelli et al. (2010) due to the presence of a zygodactyl foot 

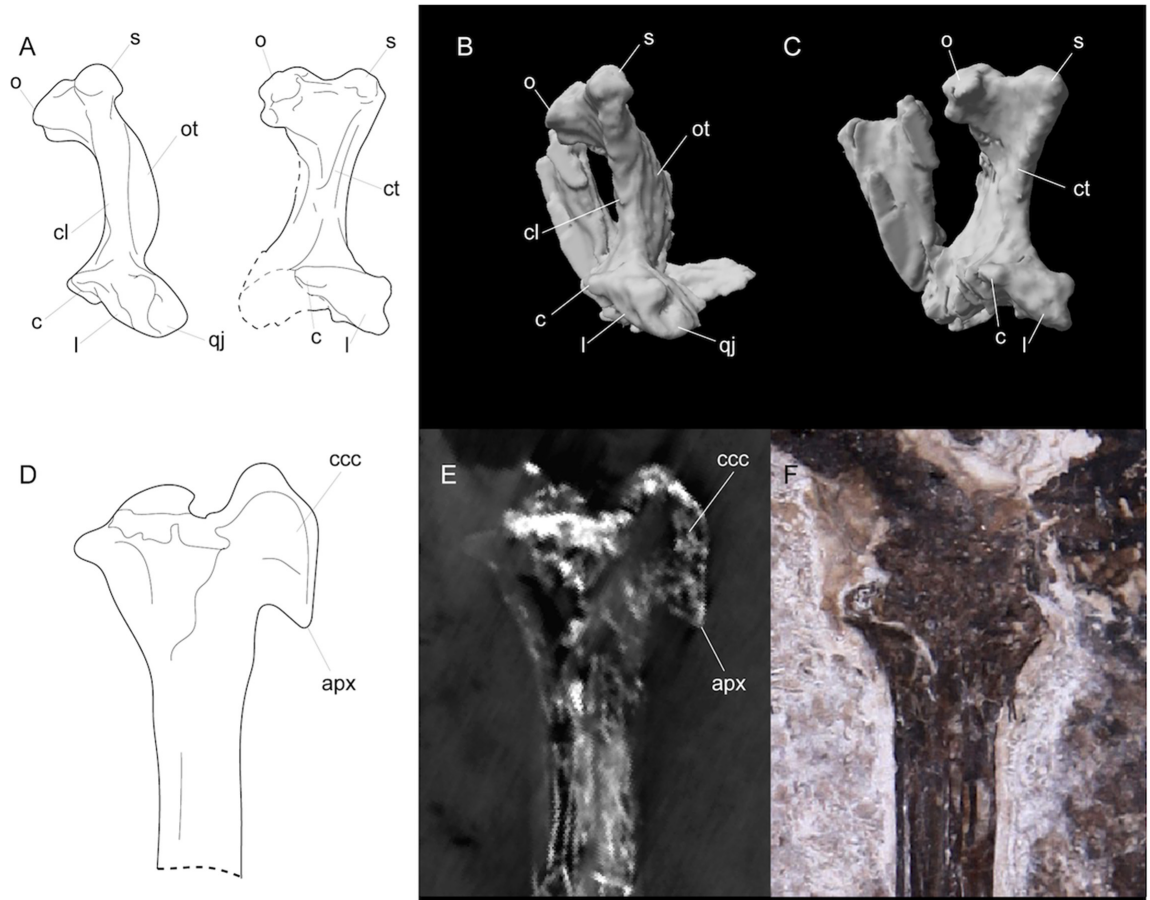

G
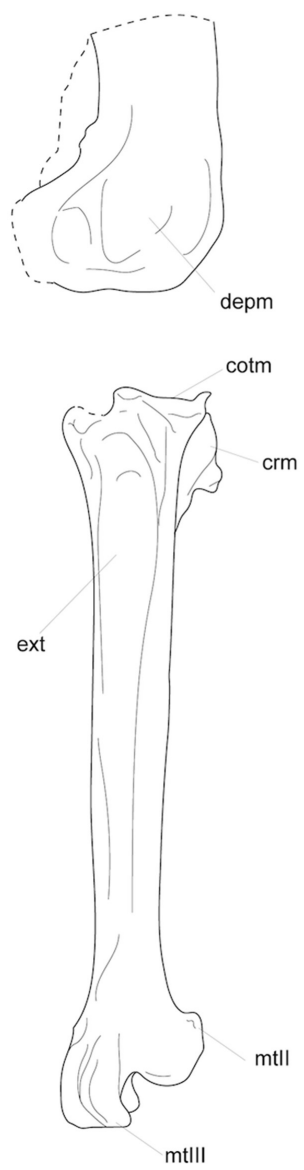

$\mathrm{H}$
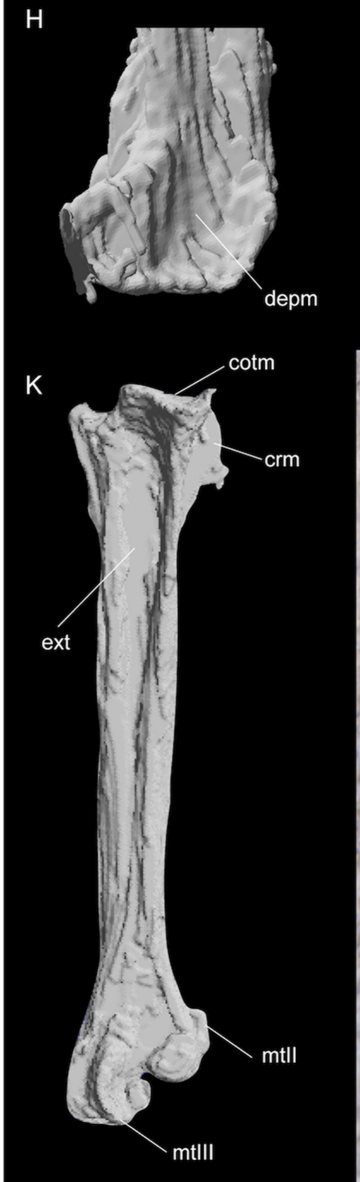

I
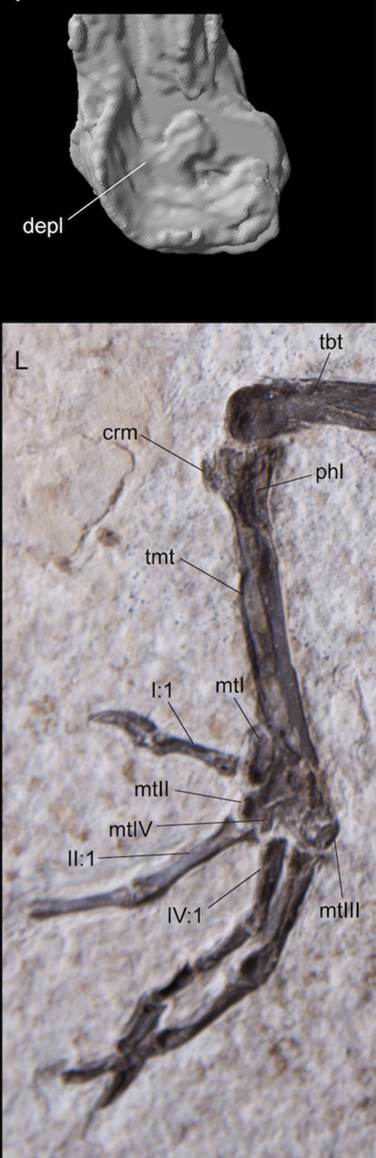
FIGURE 3 | Line drawings (A,D,G,J), segmented CT scan data (B,C,H,I,K), CT scan slice (E), and photographs (F,L) of features in FMNH PA778 recovered by CT scanning and segmentation. (A-C) depicts the quadrates; (D-F) and (G-I) shows the proximal and distal portions, respectively, of the right tibiotarsus; and (J-L) depicts the right tarsometatarsus. Anatomical abbreviations: (A-C) o, otic capitulum; s, squamosal capitulum; ot, otic process; cl, crista lateralis; ct, crista tympanica; c, caudal condyle; I, lateral condyle; qj, quadratojugal site of articulation; (D-F) ccc, crista cnemialis cranialis; apx, distal apex of crista cnemialis cranialis; (G-I) depm, depressio epicondylaris medialis; depl, depressio epicondylaris lateralis; (J-L) tbt, tibiotarsus; tmt, tarsometatarsus; cotm, cotyla medialis; crm, crista medialis; phl, fossa parahypotarsalis lateralis; ext, sulcus extensorius; I:1, hallux; mtl, metatarsal I; mtIl, metatarsal II trochlea; mtIII, metatarsal III, trochlea; mtIV, metatarsal IV trochlea; II:1, phalanx 1 of pedal digit II; IV:1, phalanx 1 of pedal digit IV.

in the latter taxon. Presence of this condition is suggested in the holotype due to a wide proximal phalanx of the fourth toe (Mayr, 2011a), and this taxon was recently phylogenetically placed within Pan-Passeriformes (Ksepka et al., 2019). N. grandei is distinguished from Salmila robusta due to possessing (1) a less decurved and less raptorial anterior terminus of the premaxilla (Figures 1, 2, prx), (2) a more caudally elongate cranium (Figures 1, 2), (3) a truncate postorbital process (Figure 2, porb), (4) a straight and dorsally oriented symphysis of the mandible that is not recurved (Figure 2, sym), (5) a decurved mandibular ramus rostral to the coronoid process (Figure 2, ram), (6) a half-moon shaped pygostyle with a caudal apex that deviates ventrally from the major axis of the pygostyle (Figure 1, pyg), (7) a more elongate pygostyle, (8) a more elongate pubis with at least $1 / 4$ of the pubis extending caudally beyond the caudal margin of the ischium (Figure 1, pub), (9) a femur that is over half the length of the tibiotarsus (Figure 1, fem), (10) a lateral condyle of the tibiotarsus that is more proximally located than the medial condyle (Figures 3G,H), (11) a deep fossa parahypotarsalis lateralis of the tarsometatarsus (Figure 3L, phl), (12) a metatarsal II trochlea with a plantarly prominent ala (Figures 1, 3J-L, mtII), (13) a metatarsal IV trochlea that is more distally extensive then the metatarsal II trochlea (Figures 3J-L, mtIV), (14) a pedal digit I: phalanx 1 that is approximately half the length of digit III: phalanx 1 (Figures 1, 3, I:1), and (15) a lack of a medially protruding flange at the proximal margin of digit IV: phalanx 1 (Figure 1, IV, see also CT, data in Supplementary Material).

\section{Description and Comparison \\ Skull}

The skull and mandible are preserved in right lateral aspect (Figures 1, 2). The tip of the premaxilla is slightly ventrally deflected, although not as deflected as that of Salmila robusta (prx, Figures 1, 2) or Cariamidae. Pitting of the rostral terminus of the premaxilla is present as in Rallidae. The rostrum is more dorsoventrally limited than that of Cariamidae. The cranial length to rostrum length ratio is roughly $1: 1$, more like that of Charadriidae than that of Haematopodidae or longbilled rallids such as Rallus. The nares are holorhinal and perforate as in Scandiavis mikkelseni (Bertelli et al., 2013), Cariamidae, four examined Charadriiformes and almost all Gruiformes (Gruiformes refers to core-Gruiformes sensu Hackett et al., 2008). They do not extend caudally beyond the zona flexoria craniofacialis as in S. mikkelseni; Songzia acutunguis Hou (1990); Psophiidae; Ralloidea; Cariamidae; and three examined Charadriiformes. In contrast, Pellornis mikkelseni exhibits true schizorhiny sensu Zusi (1984) in which its caudally acuminate nares extend caudally beyond the zona flexoria craniofacialis
(Hesse, 1990; Musser et al., 2019) The condition of this character in S. robusta (Mayr, 2000a, 2002) cannot yet be assessed due to preservation of known specimens. The narial openings are expansive both craniocaudally and dorsoventrally. The suture between the nasals and the frontal process of the premaxilla is visible, as is the midline suture of the frontal process of the premaxilla. The zona flexoria craniofacialis is broken and flattened along the right side of the rostrum but appears to have been most similar to that of Burhinidae. The antorbital angle is most similar to that of Rallus in that it is markedly acute as in Cariamidae, Heliornithidae and most examined Ralloidea and Charadriiformes. In S. mikkelseni, Psophiidae, and S. acutunguis this angle is larger and approximates a right angle. This cannot be assessed in S. robusta. As in S. acutunguis, Heliornithidae, some Rallidae, and most examined Charadriiformes, the nasal bar is broader dorsally and tapers ventrally. The dorsal and ventral portions are subequal in Cariama. A triangular maxillary process of the palatine extends caudally beyond the nasal bar in $N$. grandei, which is consistent with the condition in S. mikkelseni, Psophiidae, Aramidae, and several ralloids. This process is absent in Cariamidae and most examined Charadriiformes. Maxillopalatine processes are visible in the CT scan data (see Supplementary Material). They are triangular and exhibit small foramina, which is most similar to the condition in Gruoidea and most Charadriiformes and Ralloidea. Such foramina are much larger in Laridae and Burhinidae.

The cranium appears caudally elongate, as in many Gruiformes, and is more elongate than that of $S$. mikkelseni or S. robusta. The orbital margin is slightly crushed but forms an extensive, sharp crista that is oriented dorsolaterally as in S. mikkelseni, Himantornis haematopus (extant ralloid), Rhynochetidae, Jacanidae, Charadriidae, Burhinidae, and Pluvianidae. CT data show that this crista is also present on the left orbit and is preserved within the slab (see CT data in Supplementary Material). The ectethmoid and lacrimal are too poorly preserved to describe, other than to note that the lacrimals fuse to the skull at about the same craniocaudal location of the zona flexoria craniofacialis. It appears that fonticuli occipitales are absent from the caudal aspect of the skull as in Ralloidea, although much of the cranial anatomy cannot be discerned. A thin and linear jugal is present on the surface; with its pair visible beneath the slab in the CT scan data (see CT data in Supplementary Material). It is more slender than that of S. robusta (HLMD.Be.161; Mayr, 2002). The postorbital process is moderately small and acuminate like those of most Ralloidea. A shallow crista is located along its length to the apex, and its apex is oriented ventrally rather than cranially as in S. mikkelseni. It is smaller and more gracile than that of $S$. robusta. The 
zygomatic process appears small and acuminate, but this is difficult to ascertain due to poor preservation. The temporal fossa appears to have been shallow. At least six robust scleral ossicles are preserved. Behind them is a fonticulus interorbitalis which is rostrocaudally expansive as in S. mikkelseni, Gruidae, most Charadriiformes and Ralloidea.

Two well-preserved quadrates are present, with only one being visible above the surface; CT scan data reveal more key features of this element (Figure 3). The orbital processes are too poorly preserved for description. The posterior face between the capitula is apneumatic as in P. mikkelseni and almost all Gruiformes, whereas a foramen is present in almost all examined Charadriiformes. The medial otic capitulum is deflected caudally, as in Charadriiformes and Gruiformes. The capitula of the quadrate are moderately spaced and separated by a deep notch as in examined Rallidae and Laridae. The capitula are best preserved in the right quadrate, where they are robust and rounded like those in Laridae. The capitulum squamosum is rostrocaudally flattened as in all Charadriiformes and Gruiformes, and the capitulum oticum is mediolaterally elongate as in all examined Charadriiformes and Gruiformes. The otic processes of the quadrates are slender and more delicate like those of Ralloidea, and are much less robust than those of Gruoidea. They are recurved toward their dorsal margins. A sharp crista lateralis can be seen along the caudolateral margin of the body of the right quadrate. The prominent crista lateralis is most similar to the condition in examined rallids. A raised crista tympanica is also present as in many Gruiformes and Charadriiformes, and the otic process dorsal to this crista is deeply concave as in many Charadriiformes (e.g., Vanellus). A caudal condyle is present and visible in caudal aspect. The caudal condyle is confluent with the lateral condyle as in Gruiformes, Charadriiformes and Cariamidae. The fovea of the cotyla quadratojugalis is deep and laterally directed as in Gruiformes and Charadriiformes. Similarly, as in Ralloidea and many Charadriiformes, a rounded processus lateralis present along the caudodorsal rim projects over the fovea quadratojugalis.

The caudal terminus of the dentary is slightly dorsally convex as in Psophiidae, but this is difficult to ascertain due to breakage. The dorsal ramus of the dentary is short relative to the ventral ramus. The angular is almost in line with the rest of the mandible and not as decurved as that of S. robusta, and is more like those of S. mikkelseni, Gruiformes and Charadriiformes. The rostral mandibular fenestrae appear to have been elongate and slit-like, with extremely small caudal mandibular fenestrae if present. The caudal articular area displays neoavian morphology, and a narrow, dorsally projecting hooklike projection is present as in Gruiformes, Charadriiformes and P. mikkelseni (Musser et al., 2019).

\section{Axial skeleton}

Crushed remains of what appears to be the atlas in lateral view are located just below the occipital, but the CT scan does not reveal additional diagnostic morphology of the atlas or axis. At least 18 articulated presacral vertebrae are preserved, mostly in lateral aspect. The spinous processes are dorsoventrally truncate and located at approximately the midline of each cervical vertebra. Elongate costal processes are apparent, as in all examined Charadriiformes and Gruiformes; S. mikkelseni; and Messelornis cristata Hesse (1988). They are located relatively rostrally, in contrast to the more caudally located costal processes of Psophiidae. Costal processes are present throughout the series with the exception of the caudal-most cervical vertebrae, although these may be obscured by other bone or matrix. This is similar to the condition in most examined Gruiformes and Charadriidae. The caudal zygapophyses are elongate and taper distally. They are oriented more dorsally than those of Rallidae or Charadriidae, although those of Charadriidae are closer to this condition. Vertebrae preserved in lateral view appear to be laterally concave. A notarium superficially appears to be present; however, CT scan data reveals that it is absent, unlike the condition in Psophiidae. The presence or absence of a notarium is currently unknown in S. robusta.

Computed tomography scan data reveal what appear to be fragmented remains of the sternum; however, no diagnostic features can be discerned if this interpretation is correct. Several ribs are preserved in lateral aspect. The cranialmost uncinate process is truncate and broad, but the uncinate processes caudal to that are more elongate and slender. The pygostyle is preserved in lateral aspect along with several poorly preserved caudal vertebrae. It is ventrally recurved and "half-moon" shaped, with the terminus of the pygostyle deviating ventrally from its major axis as in S. mikkelseni and some Charadriidae. It appears to be mediolaterally flattened save for a slight expansion at the dorsocaudal edge. The neural spines of the caudal vertebrae preserved in articulation with the pygostyle are robust, dorsally blunted and angled caudally. One free caudal vertebra is preserved separate from the pygostyle and other caudal vertebrae and is visible in what appears to be posterior aspect underlying the soft tissue. It bears a truncate neural spine and elongate transverse processes that are angled ventrally by approximately 15 degrees from the horizontal position.

\section{Pelvic Girdle}

The remains of the pelvis are poorly preserved and obscured by both matrix and preserved plumage. Visible portions comprise the ventral aspect of the right preacetabular ilium, the lateral aspect of the right postacetabular ischium, most of the obturator foramen, the entirety of the right pubis, and a small and broken portion of the midshaft of the left pubis.

The pelvis appears to have been dorsoventrally flattened. The preacetabular ilium is broken along the proximal and medial margins but is proximally expansive and wing-like, as in examined Charadriiformes and S. mikkelseni. The obturator foramen is craniocaudally elongate and ovoid. It is not delimited caudally, but it is uncertain whether this is due to taphonomy. The shape of the obturator foramen is most similar to the condition in Psophiidae and Charadriiformes as it is dorsoventrally wide and broadens caudally, whereas in examined Rallidae the obturator foramen is extremely dorsoventrally flattened. As in many Charadriiformes and Heliornithidae the pubis is extremely long, approximately twice the length of the postacetabular ilium. This is unlike the condition in Sarothruridae, Rallidae and S. robusta in which 
the postacetabular ischium and pubis are of subequal length (HLMD.Be.161; Mayr, 2002). The pubis tapers to an acuminate point and superficially appears thin and rounded; however, CT scan data reveals that it is broad and flattened as in examined Gruiformes, Cariamidae, and S. robusta (SMF-ME 3014; Mayr, 2000a). The fenestra ischiopubica appears to have been dorsoventrally expansive as in examined Charadriiformes and S. mikkelseni. The terminal process of the ischium is caudally elongate and appears to taper caudally as in many Charadriiformes, unlike the condition in Gruiformes and S. robusta. The caudolateral vertex of the ilium is present. It is broad at the base, rounded at the terminus and is dorsocaudally directed and truncate. The CT data present this feature as being most similar to that of S. mikkelseni in shape and direction of projection (see Supplementary Material). When compared to extant taxa the condition in $N$. grandei is most similar to the condition in Turnicidae and some rallids. The caudal terminus of the ilium is markedly cranial to that of the ischium, as in S. mikkelseni and many charadriiform taxa such as Pluvianidae and Burhinidae.

\section{Hindlimb}

An articulated right leg is preserved. The femur is poorly preserved in caudolateral view. It is more robust and elongate compared to the femur of S. mikkelseni. The trochanteric crest and distal condylar area have been obliterated.

The tibiotarsus and articulated fibula are, similarly, poorly preserved in caudo-lateral aspect. The tibiotarsus is approximately twice the length of the tarsometatarsus like in S. mikkelseni and examined Ralloidea. The tarsometatarsus is markedly longer in S. robusta, comprising over half the length of the tarsometatarsus (see HLMD.Be.161, Mayr, 2002). The condition in $N$. grandei also differs from that observed in Psophiidae, Burhinidae and Cariamidae in which the tarsometatarsus length is over half the length of the tibiotarsus. The tibiotarsus of $N$. grandei is shorter than that of S. robusta as well (see Table 2). The fibular head is crushed onto the head of the tibiotarsus. A narrow proximal interosseous foramen can be discerned but its true shape and proximodistal length is unknown due to taphonomic distortion. Morphology of the crista cnemialis has been obliterated on the surface, but CT scan data reveal a prominent, hook-like crista cnemialis cranialis that is limited craniocaudally but proximodistally expansive, as in S. mikkelseni and examined Rallidae. Psophiidae, Cariamidae and Burhinidae also have a well projected crista cnemialis cranialis; however, they are more craniocaudally expansive and are more proximodistally limited in Psophiidae and Burhinidae. The lateral face of the distal condylar area is visible. The depressio epicondylaris lateralis is deep, like that of most Ralloidea and unlike the more shallow depressions of $S$. mikkelseni and most Gruoidea and Charadriiformes; however, the caudal rim of the condyle is more prominent and laterally extensive than those of Ralloidea. The sulcus m. fibularis appears shallow. CT scan data reveal what appears to be a prominent tubercle laterodistal to the pons supratendineus, like the condition in most Gruiformes. Medial and lateral condyles that exhibit subequal cranial projection are also visible in the CT scan data. The lateral condyle is proximodistally more elongate and mediolaterally narrower than the medial condyle. As in S. robusta, the distal rim of the medial condyle is not notched. This is unlike the condition in S. mikkelseni, Gruoidea, Rallidae, and many Charadriiformes. No ossified tendons are present along the tibiotarsus, which are present in Gruoidea, Sarothruridae and several rallids.

The tarsometatarsus is preserved in caudolateral aspect. CT scan data reveal a prominent eminentia intercotylaris and a deep fossa infracotylaris dorsalis. The cotyla lateralis is distal to the cotyla medialis as in all examined Charadriiformes and Gruiformes. The medial margin of the medial cotyle is prominently projected proximally and forms a sharp crista as in S. mikkelseni, P. mikkelseni, Jacanidae, Pluvianidae, Laridae, Haematopodidae, Recurvirostridae, Thinocoridae, Turnicidae and Gruiformes and unlike the condition in Cariamidae. The hypotarsal crests are moderately projected, with the medial crest being projected farther plantar than the lateral crest. This condition is also present in S. mikkelseni, S. robusta, P. mikkelseni, M. cristata, and all examined Charadriiformes and Gruiformes. At least one canal appears to be present in the hypotarsus as revealed by the CT scan data, but its homology is uncertain. The fossa parahypotarsalis lateralis is deep as in M. cristata and many examined Charadriiformes and Gruiformes. This feature is shallow in S. mikkelseni. The sulcus extensorius is markedly deep along the shaft of the tarsometatarsus. Metatarsal I is truncate and rounded distally. It inserts into a notch in the medial side of the tarsometatarsus, but matrix obscures the articular site. The metatarsal II trochlea is extremely plantarly deflected as in S. mikkelseni, M. cristata, S. acutunguis, Gruiformes, and all examined Charadriiformes except Burhinidae, Stercorariidae, and Turnicidae. This condition is not present in S. robusta or Cariamidae. This trochlea also bears a prominent plantar ala as in S. mikkelseni, M. cristata, Gruiformes, and Charadriiformes; this feature is absent in S. robusta and Cariamidae. CT scan data reveal a deep central groove that runs along at least the dorsal length of the metatarsal III trochlea. The metatarsal III trochlea extends farther distally than the trochleae for metatarsals II and IV, with the metatarsal IV trochlea extending further distally than that of metatarsal II. This condition is present in S. mikkelseni, M. cristata, and most examined Gruiformes; in Cariamidae and S. robusta, the condition is similar but differs in that the distal extents of the trochlea for metatarsals II and IV are subequal. No ossified tendons are present along the tarsometatarsus.

All pedal phalanges are preserved with the exception of the unguals of digits II and III. The phalanges are less robust than S. robusta. They are shorter and much more delicate than those of Rallidae, and in this way are more similar to those of Charadriidae. In N. grandei the first phalanx of each digit is more elongate than the subsequent phalanges. The unguals of digits I and IV are truncate and have deep lateral sulci. At the proximal end, phalanx II:1 (digit: phalanx) has a strong flange at the plantolateral corner. The trochleae appear asymmetrical on both II:1 and II:2, with the lateral rim being farther projected. The robust, medially projected flange seen in S. robusta in IV:1 is not present in N. grandei. 


\section{Possible Syrinx and Trachea}

Tracheal rings are pervasive and thick, and a possible syrinx is present above the cranium (Figures 1, 2, see also.stl files in Supplementary Datasheet 1). Future imaging and comparison will allow determination of this feature. The tracheal rings appear wider than those of S. robusta (HLMD.Be.161; Mayr, 2002), although this is difficult to ascertain in the specimen of S. robusta. There is a thick band of rings, a ring with a chevron-like midline connection and then two sets of rings representing bifurcation caudal to the possible syrinx.

\section{Plumage}

Individual small contour feather outlines can be seen particularly near the occipital cranium, cervical vertebrae, dorsal body, proximal chest, upper hindlimbs (femur and tibiotarsus), and pygostyle. The tail looks to have been broad and elongate with a shallowly forked tip. The tail comprises large, rectangular feathers largely made up of pars pennacea of vexillum while shorter feathers that appear to comprise pars plumacea of vexillum cover the rest of the body. Rachides and some barbs can be seen, but the number of individual tail feathers cannot be counted due to preservation.

\section{MATERIALS AND METHODS}

\section{Comparative Materials}

Specimens used for description and phylogenetic analyses came from the Bird Division of FMNH, the Ornithology Department of $\mathrm{AMNH}$, and the Ornithology Department of USNM. Osteological terminology largely follows Baumel and Witmer (1993). Specimen numbers for comparative material are provided in Table 1.

\section{CT Scanning}

The holotype specimen was scanned using dual tube $\mathrm{x}$-ray computed tomography at the PaleoCT Lab at the University of Chicago, which can scan specimens with a resolution of up to $0.4 \mu \mathrm{m}$. As the specimen slab was large, it was scanned using a two-part multiscan that was combined to form one image sequence. The voxel size of the combined scan is 79.0540. The specimen is housed in the Department of Geology of FMNH. CT data generated during the current study are available in the Supplementary Datasheet 1 via Morphobank (O'Leary and Kaufman, 2012) under Project $3614^{1}$.

\section{Character Matrix}

The data matrix is built on that of Musser and Cracraft (2019) following the methodology discussed in that publication, but has expanded since that publication to comprise 693 discrete morphological characters and 60 taxa, eight of which are extinct. Character descriptions are provided in the Appendix and the data matrix has been made publicly available on Morphobank (O’Leary and Kaufman, 2012) under Project 3614

\footnotetext{
${ }^{1}$ http://morphobank.org/permalink/?P3614
}

see text footnote 1 . In addition to the methods outlined in Musser and Cracraft (2019) and creation of most characters from direct observation of avian skeletons, characters from several previously published morphological datasets (Strauch, 1978; Cracraft and Clarke, 2001; Ferreira and Reginaldo, 2005; Livezey and Zusi, 2006; Mayr, 2008, 2013), especially those that focused on Charadriiformes (Livezey, 2009, 2010; Mayr, 2011b), were evaluated for use in this iteration of the dataset. Specimen numbers for examined taxa are presented in Table 1. Salmila robusta was added and scored based on Mayr (2000a, 2002) as FMNH PA 778 was previously considered to be closely related to that taxon (Grande, 2013). Scandiavis mikkelseni (Bertelli et al., 2013) and distal humeri IGM 100/1435 (Pan-Charadriiformes, Hood et al., 2019) and SMF AV 619 (Charadriiformes indet., Mayr, 2016) were added and scored from photographs presented in those publications as they have been hypothesized to be extinct exemplars of Charadriiformes and S. mikkelseni shares several features with FMNH PA 778. Two species of Morsoravis, Morsoravis sedilis (Bertelli et al., 2010; Mayr, 2011a) and an undescribed Morsoravis sp. FMNH PA789 (see photograph of specimen published by Grande, 2013) were included in initial analyses as Morsoravis was originally hypothesized to be charadriiform (Bertelli et al., 2010); however, we subsequently removed it as Morsoravis is now known to be placed within pan-Passeriformes (Ksepka et al., 2019). Pellornis mikkelseni, Messelornis cristata, and Songzia acutunguis were included as they potentially represent stem Ralloidea (Musser et al., 2019), and FMNH PA778 presented a composite of charadriiform-like and gruiform-like features. The final scorings for each of these taxa are composites of scorings across several specimens from both in-person study and photographs from published studies: Bertelli et al. (2011); Musser et al. (2019) for P. mikkelseni; Hesse (1990); Bertelli et al. (2011) for M. cristata; and Wang et al. (2012) for $S$. acutunguis.

\section{Phylogenetic Analyses}

We performed unconstrained heuristic parsimony analyses of the dataset in PAUP* (Swofford, 2002); Version 4.0a166, build $164(\times 86)$ using 10,000 random taxon addition replicates per run. Heuristic search algorithms were used. Tree bisectionreconnection branch swapping was employed and minimum branch lengths valued at zero were collapsed, following Mayr and Clarke (2003), Musser and Cracraft (2019). No character weighting was applied. Characters 245, 320 and 688 were ordered, following Bertelli et al. (2011); Musser et al. (2019). Bootstrap analyses were performed using 500 bootstrap replicates each with 10 random taxon addition replicates as in Mayr and Clarke (2003). In addition to unconstrained analyses, constrained analyses were performed using the topology of recent phylogenomic studies (Prum et al., 2015; Reddy et al., 2017; Kimball et al., 2019) as molecular backbone constraints for the major clades of sampled extant taxa except for Opisthocomus hoazin due to current lack of robust placement of that taxon even among these recent molecular studies. Extinct taxa were unconstrained in all analyses. 


\section{Body Size Estimation}

Femur length was the best predictor of body mass in extant volant birds $\left(\mathrm{R}^{2}=0.9028\right.$; Field et al., 2013) that could be obtained from FMNH PA778 and Scandiavis mikkelseni (Bertelli et al., 2013).

\section{RESULTS}

Unconstrained parsimony analysis resulted in 69 most parsimonious trees (MPTs) of 5,147 steps. This analysis recovered a paraphyletic Gruiformes with respect to Charadriiformes, with Nahmavis grandei and Scandiavis mikkelseni being placed as the sister-taxa of all included Charadriiformes $(\mathrm{CI}=0.166$, $\mathrm{RI}=0.475, \mathrm{RC}=0.079, \mathrm{HI}=0.834)$.

Analysis applying a backbone constraint representing major subclade relationships of Kimball et al. (2019) recovered 56 MPTs of 5,248 steps (Figure 4; $\mathrm{CI}=0.163, \mathrm{RI}=0.462, \mathrm{RC}=0.075$, $\mathrm{HI}=0.838$ ) and a clade containing $N$. grandei, Turnix nigricollis and S. mikkelseni as the sister-group of all other included Charadriiformes. Synapomorphies recovered for critical groups across all constrained analyses are displayed in Supplementary Table 1. Pellornis mikkelseni was recovered as a messelornithid across all analyses, consistent with prior placements (Bertelli et al., 2011; Musser et al., 2019). Messelornithidae (Pellornis mikkelseni + Messelornis cristata) was placed as the sister-taxon of Songzia acutunguis. Messelornithidae was within a clade sister to extant Ralloidea across all analyses. This is consistent with the three derived characters described by Mayr (2004) as evidence of a monophyletic (Messelornithidae + (Rallidae + Heliornithidae)) clade and with the phylogenetic analyses of Musser et al. (2019) which recovered a Messelornithidae (including Pellornis mikkelseni) + Ralloidea clade.

Analyses using a backbone constraint based on the major clade relationships of Prum et al. (2015) recovered 75 MPTs of 5,244 steps (Figure 5A; $\mathrm{CI}=0.163, \mathrm{RI}=0.463, \mathrm{RC}=0.075, \mathrm{HI}=0.837$ ), and employing a Reddy et al. (2017) constraint yielded 84 MPTs of 5,260 steps (Figure 5B; CI $=0.162$, RI $=0.461, R C=0.075$, $\mathrm{HI}=0.838$ ). These analyses did not recover Charadriiformes and Gruiformes as sister-groups as in the Kimball et al. (2019) constrained analysis. They resulted in placement of $N$. grandei and S. mikkelseni in a clade containing Messelornithidae that made up the sister-group of extant ralloids, with $S$. acutunguis being placed within crown Ralloidea (Figure 5). When the Messelornithidae were removed, analyses employing the Prum et al. (2015) backbone constraint again placed N. grandei and S. mikkelseni as sister-taxa within Charadriiformes, and analyses using the Reddy et al. (2017) constraint resulted in collapse of the relationships of all included Charadriiformes, N. grandei and S. mikkelseni into a polytomy at the base of Neoaves. Bootstrap support for placement of extinct taxa was less than 50\% across all analyses, with the exception of Messelornithidae earning an 88\% bootstrap score in each result.

Salmila robusta was recovered within a clade containing the Cariamidae, Cathartes burrovianus and Leptosomus discolor under Prum et al. (2015) and Kimball et al. (2019) constraints as the sister-taxon of L. discolor. Analyses employing the Reddy et al. (2017) constraints recovered S. robusta within a clade containing the Eurypygiformes, Caprimulgus carolinensis and Columba livia with $S$. robusta placed as the sister-taxon of the Eurypyga helias + Rhynochetos jubatus sister-group. The latter difference in placement may be due to a lack of scorings for $S$. robusta as the specimen was scored from published photographs.

Both Eocene humeri (IGM 100/1435 from Mongolia and SMF AV 619 from Virginia) were recovered within crown Charadriiformes across all analyses, and IGM 100/1435 was placed as the sister taxon of Chionis alba under both the Prum et al. (2015) and Kimball et al. (2019) backbone constraints. Messelornithidae is recovered as being within a sister-clade of Ralloidea across all analyses, bolstering evidence for placement of Messelornithidae at the base of Ralloidea as originally recovered by Musser et al. (2019); however, further resolution of taxa such as S. mikkelseni and N. grandei must be completed to more confidently place this clade. S. acutunguis is consistently recovered as either a sister-taxon of Messelornithidae or as being unresolved within crown Ralloidea, suggesting that it may be more closely related to crown ralloids than the Messelornithidae. Additional fossils still need to be included to more robustly place this taxon (Wang et al., 2012; Musser et al., 2019).

A rough mean body mass estimate for FMNH PA778 is approximately $200 \mathrm{~g}$ based on published allometric equations using femoral length (Field et al., 2013). This is larger than the estimated body masses for Scandiavis mikkelseni and Pellornis mikkelseni (170.24 g and $133.28 \mathrm{~g}$, respectively). This estimate would make $N$. grandei somewhat smaller than Dromas ardeola (325 g), Ibidoryncha struthersii (294 g) and roughly similar in size to some members of Laridae, Charadriidae (larger members of Vanellus), Recurvirostridae (most consistent with avocets), and Scolopacidae but not approaching the masses of larger shorebirds such as many members of Haematopodidae, Burhinidae, Chionidae, and Sterocoraiidae ( 600 to over $1000 \mathrm{~g}$; Dunning, 2007). The mean mass estimate for S. mikkelseni aligns it more closely in size with Jacanidae, the smallest members of Recurvirostridae (e.g., Himantopus), some members of Charadriidae (Vanellus), and smaller members of Scolopacidae and Laridae.

\section{DISCUSSION}

Nahmavis grandei is recovered as a charadriiform when enforcing avian subclade relationships recovered in Kimball et al. (2019). This result is significant not only because $N$. grandei may be the first known charadriiform from the Green River Formation, but also because the Paleogene record of this group remains globally sparse (Mayr, 2009, 2017). At the same time, recovery of N. grandei within basal Gruiformes under the Prum et al. (2015) and Reddy et al. (2017) constraints problematizes that proposed assignment. Specifically, it highlights the sensitivity of the placement of potential stem Charadriiformes to resolution of neoavian subclade relationships. Despite inclusion of wellpreserved charadriiform and gruiform fossils with articulated skeletons within a large morphological data matrix, the finescale relationships of $N$. grandei and S. mikkelseni remain weakly supported. They are sensitive to phylogenetic placement of extant 


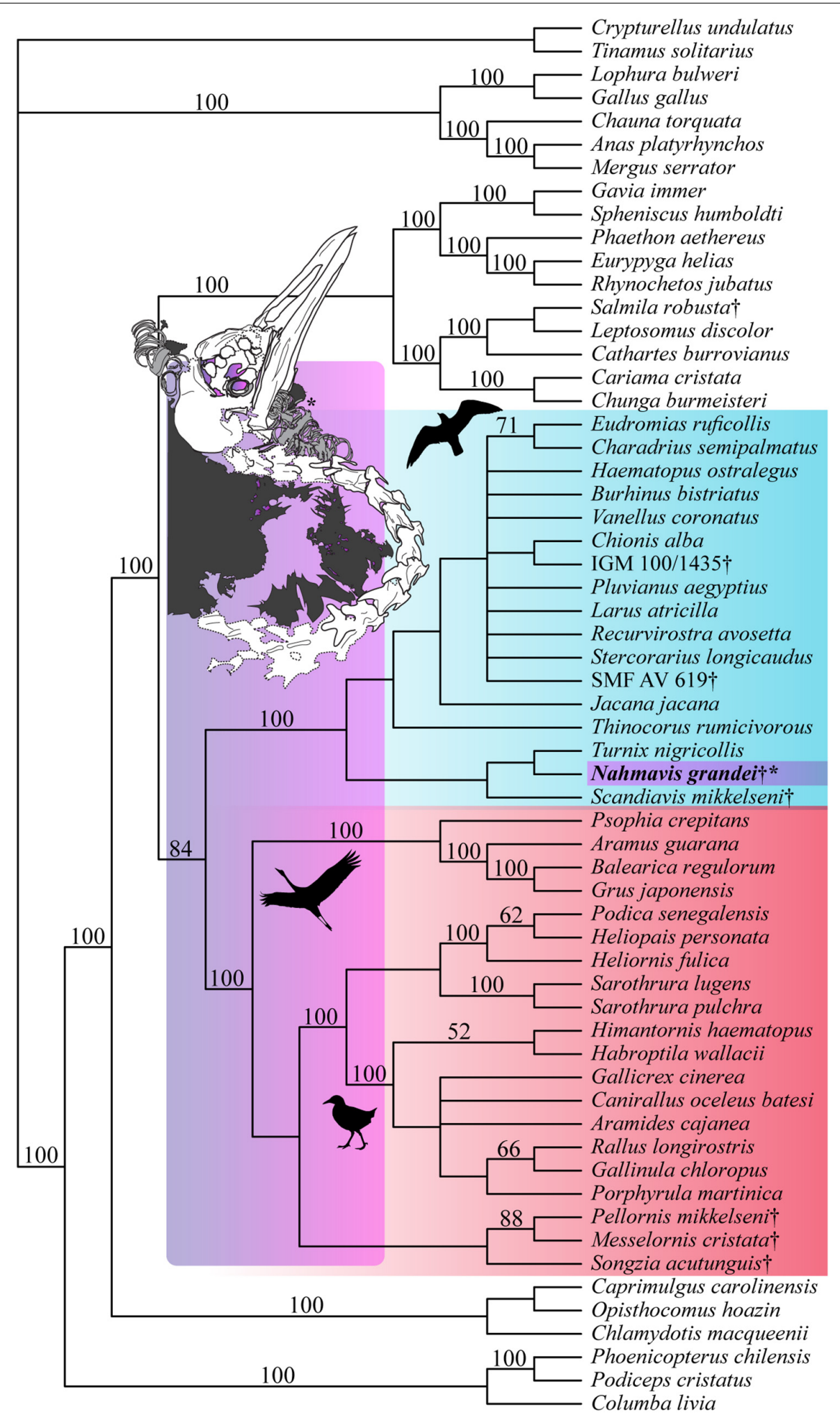

FIGURE 4 | Strict consensus tree of 56 MPTs of 5,248 steps recovered using the most recent Kimball et al. (2019) tree as a molecular backbone constraint $(\mathrm{Cl}=0.163, \mathrm{RI}=0.462, \mathrm{RC}=0.075, \mathrm{HI}=0.838)$. Charadriform, gruoid and ralloid silhouettes are placed at the crowns of their respective clades. Charadriformes are highlighted in blue, Gruiformes are highlighted in red, and violet spans the possible phylogenetic placements of Nahmavis grandei across these clades. All extinct taxa are denoted with daggers. Bootstrap support values greater than $50 \%$ are denoted above branches. 

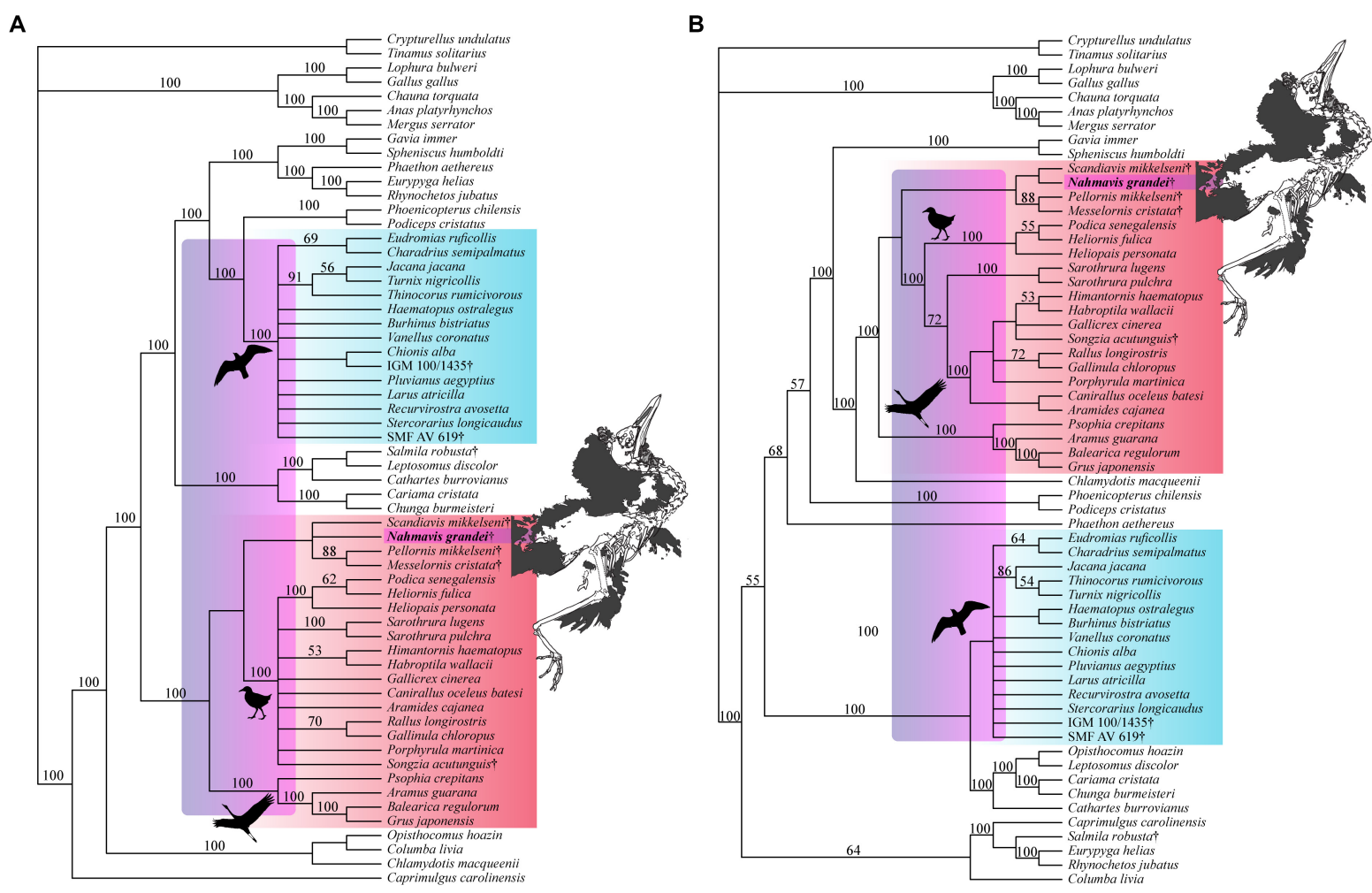

FIGURE 5 | Strict consensus trees recovered from heuristic parsimony analyses using (A) Prum et al. (2015) (75 MPTs, 5,244 steps, Cl = 0.163, RI = 0.463, $\mathrm{RC}=0.075, \mathrm{HI}=0.837$ ) and (B) Reddy et al. (2017) (84 MPTs, 5,260 steps, $\mathrm{Cl}=0.162, \mathrm{Rl}=0.461, \mathrm{RC}=0.075, \mathrm{HI}=0.838$ ) trees as molecular backbone constraints. Charadriiform, gruoid and ralloid silhouettes are placed at the crowns of their respective clades. Charadriiformes are highlighted in blue, Gruiformes are highlighted in red, and violet spans the possible phylogenetic placements of Nahmavis grandei across these clades. All extinct taxa are denoted with daggers. Bootstrap support values greater than $50 \%$ are denoted above branches.

clades, especially in phylogenies where Charadriiformes is not recovered as the sister-group of Gruiformes as is the case in the analyses by Prum et al. (2015) and Reddy et al. (2017). A Charadriiformes + Gruiformes sister-taxon relationship has been recovered by phylogenies using a variety of datatypes, including those presented in recent molecular studies (e.g., Cracraft, 1988; van Tuinen and Hedges, 2001; Livezey and Zusi, 2007; Bertelli et al., 2011; Jarvis et al., 2014; Kimball et al., 2019; Musser and Cracraft, 2019). As discussed below, traits such as having a crista tympanica of the quadrate with a terminus within the ventral half of the otic process, unfused iliac blades of the pelvis, and a pedal digit I: phalanx 1 that is half the length of pedal digit III: phalanx 1 are present in parts of both clades.

Six unambiguous and three ambiguous optimized synapomorphies of the skull, cervical vertebrae, pelvis and hallux with $\mathrm{CI}<1.0$ support placement of $N$. grandei within Charadriiformes using the Kimball et al. (2019) constraint (Figure 6). The nasal bar is rostrocaudally wider at the caudodorsal margin of the nares than at the caudoventral margin in $N$. grandei and many Charadriiformes (character 16: state 2 , unambiguous), whereas the opposite is true in most gruoids (16:3) and the margins are subequal in rostrocaudal width in most Ralloidea (16:1). The quadrate in N. grandei and most Charadriiformes has a crista tympanica that terminates within the ventral half of the otic process (180:2, unambiguous), is deeply concave along the caudal face of the otic process dorsal to the crista tympanica (183:2, unambiguous), and has a lateral condyle that terminates well ventral to the ventral margin of the caudal condyle (206:2, ambiguous); in contrast, almost all included Gruiformes have a crista tympanica that terminates at the dorsoventral midpoint or within the dorsal half of the otic process (180:1) and a shallowly excavated or convex caudal face of the otic process (183:1). Most included Gruiformes do share marked ventral location of the ventral margin of the lateral condyle relative to the caudal condyle (206:2). Relative elongation of intermediate cervical vertebrae is lost in $N$. grandei (Figures 1, 2), S. mikkelseni, and most Charadriiformes (253:2, ambiguous), but is present in most Gruiformes (253:1). The iliac blades of the pelvis are not fused to the synsacrum (498:2, unambiguous, Figure 6). Pedal digit I: phalanx 1 is half the length of pedal digit III: phalanx 1 (691:2, unambiguous) in N. grandei, S. mikkelseni and almost all Charadriiformes. In all extant Gruiformes, the iliac blades are fused to the synsacrum (498:1) and pedal digit I: phalanx 1 is more elongate (691:1). A medially protruding flange at the proximal margin of pedal digit IV: phalanx 1 is absent in $N$. grandei (692:0, ambiguous, see CT data in Supplementary Material) and present in some Gruiformes (692:1). This character could not be assessed for 


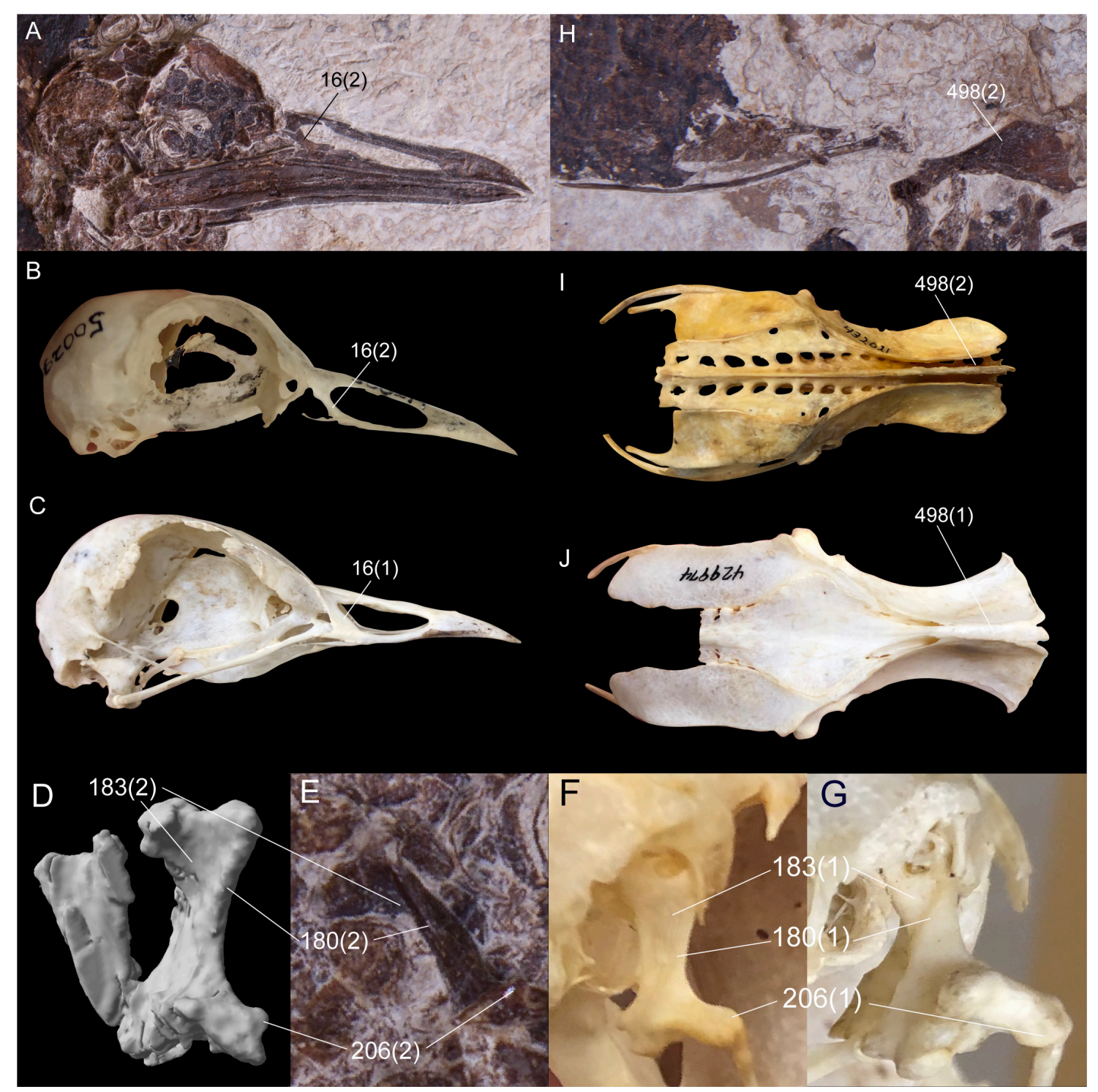

FIGURE 6 | Comparison of selected optimized synapomorphies that place Nahmavis grandei within Charadriiformes to the exclusion of Gruiformes under the Kimball et al. (2019) backbone constraints. Synapomorphies are shown with the character number followed by the state in parentheses. (A-C) Skulls of N. grandei, Pluvianus aegyptius, and Psophia crepitans. (D,E) segmented CT image and photograph of the right quadrate of $N$. grandei. (F,G) right quadrates of Vanellus coronatus and P. crepitans. (H-J) pelvises of N. grandei, Burhinus bistriatus and P. crepitans.

included Charadriiformes. The placement of Turnix nigricollis as the sister-taxon of $N$. grandei is not consistent with recent phylogenies, which recover Turnix as the sister-taxon of a group containing Glareola, Larus, and Dromas (Prum et al., 2015; Reddy et al., 2017; Kimball et al., 2019). In some analyses, this group also contains Uria, Sterna, Chroicocephalus, and Rynchops (Prum et al., 2015; Kimball et al., 2019). Incongruous placement of this taxon in our results is likely due to a lack of constraining taxon relationships within major subclades and a need for more taxon and character sampling. Turnix is also known to be problematic in morphological analyses; Livezey (2010) similarly recovered Turnix as the sister-group to all other Charadriiformes, and Mayr (2011b) recovered
Turnicidae as either within a polytomy in Charadriiformes or as the sister-taxon of a clade containing Jacanidae, Scolopacidae, Rostratulidae, Thinocoridae, and Pedionomidae.

Several characters that were recovered as support for placement of N. grandei within Charadriiformes in the analysis employing the Kimball et al. (2019) constraint were also recovered as supporting a clade containing $N$. grandei, S. mikkelseni and the Messelornithidae under the Prum et al. (2015) and Reddy et al. (2017) backbone constraints. Character evidence for placement of $N$. grandei within this group across both analyses comprises a maximum of five unambiguous synapomorphies. As in the placement of N. grandei under the Kimball et al. (2019) constraints, the quadrate in N. grandei 
has a crista tympanica that terminates ventrally within the ventral half of the otic process (180:2, unambiguous), the iliac blades of the pelvis are not fused to the synsacrum (498:2, unambiguous), and pedal digit I: phalanx 1 is half the length of pedal digit III: phalanx 1 (691:2, unambiguous). In addition, a pronounced epicondylus lateralis tubercle of the tibiotarsus is present in N. grandei (609:2, unambiguous under the Prum et al. (2015) constraints and ambiguous under the Reddy et al., 2017 constraints) that is diminished in most extant Gruiformes and derived Charadriiformes (609:1). The fossa supratrochlearis plantaris of the tarsometatarsus is distinctly concave as in most examined Charadriiformes (677:1, unambiguous) and to the exclusion of most Gruiformes.

In addition to the issues discussed above, a lack of the pectoral girdle and forelimb in both N. grandei and S. mikkelseni may be the cause of these different optimizations under several backbone constraints. Musser et al. (2019) found two out of three synapomorphies for a clade containing Messelornithidae and Songzia acutunguis to be located within the humerus and sternum. The direction and development of the dorsal supracondylar tubercle of the humerus is one of the few proposed unambiguous crown traits present in Paleogene material referred to Charadriiformes (Mayr, 2016; Hood et al., 2019).

Shared characters due to a similar ecology in N. grandei, S. mikkelseni and the messelornithids cannot be ruled out. The short pedal digit I: phalanx 1 of $N$. grandei, S. mikkelseni, and $M$. cristata (unknown in P. mikkelseni) and the longer pedal digit IV: phalanx 4 than IV:3 observable in both $N$. grandei and M. cristata (unknown in S. mikkelseni and P. mikkelseni) suggests some degree of terrestrial or cursorial adaptation (Storer, 1971; Zeffer et al., 2003). In M. cristata, specifically, the proximal articulation of the hallux has been proposed to render it immobile (Hesse, 1990). The shorter tarsometatarsus relative to the tibiotarsus in $N$. grandei is distinct from the more subequal elements of $S$. mikkelseni and $M$. cristata, suggesting that S. mikkelseni could have been more likely to run and wade along the shoreline like a traditional sandpiper than N. grandei. Most of the foot is missing in $P$. mikkelseni and key pedal phalanges are not preserved in S. mikkelseni, again limiting ecological comparison and data for phylogenetic analyses. A high degree of shared plesiomorphy may be expected if Charadriiformes and Gruiformes are sister-taxa or homoplasy may be indicated due to similar ecology if they are not. The scorings for the Messelornithidae and $N$. grandei are nearly identical, with few differences between either Pellornis or Messelornis and $N$. grandei and even fewer differences between $N$. grandei and both examined Messelornithidae. The differences between $N$. grandei and both examined Messelornithidae comprise the following features: $N$. grandei lacks the pneumatic foramen present on the caudal face of the quadrate between the capitula of Messelornis and Pellornis, the apices of spinous processes of the cervical vertebrae are more elongate and caudally reaching in the Messelornithidae than in N. grandei, the caudal terminus of the pygostyle of $N$. grandei departs ventrally from the craniocaudal axis whereas it departs from this axis dorsally in the Messelornithidae, the mediolateral thickness of the medial and lateral condyles of the tibiotarsus are subequal in $N$. grandei whereas the medial condyle is mediolaterally thinner in the Messelornithidae, and the ossified retinaculum present in the tibiotarsus in both examined members of Messelornithidae is absent in N. grandei. All differences, even those between one examined member of Messelornithidae and $N$. grandei, comprise features that have variable scorings across Gruiformes and Charadriiformes and thus remain cryptic in terms of indicating a more dominant affinity.

A feature of the feathering in $N$. grandei that requires further study and could be alternatively plesiomorphic to a charadriiform-gruiform clade or independently derived in early parts of both clades is the elongate, shallowly cleft tail shape (Figure 1), which appears to be most similar to that of an Oystercatcher or Egyptian Plover. It is unlike that of any extant gruiform (del Hoyo et al., 2020). The tail length may have allowed for additional lift (Thomas, 1993), balance and increased flight maneuverability, perhaps to aid in feeding overwater like a gull (Thomas and Balmford, 1995). The holotype of $P$. mikkelseni also appeared to have a broad and elongate tail, but its terminal shape is unknown (Bertelli et al., 2011; Musser et al., 2019).

Phylogenetic placement of these Paleogene fossils has implications for the timing of charadriiform diversification. The isolated early Eocene humeri are always recovered as part of that clade. If all specimens are assessed to that clade, they would indicate that both stem and crown taxa were present in both marine and lacustrine environments around the same time across the globe, consistent with a rapid evolutionary radiation. Placement of the two humeri within crown Charadriiformes suggests that they may be useful fossils for calibration, older than even the middle Eocene Jiliniornis huadianensis Hou and Ericson (2002) recently proposed as the calibration for crown Charadriiformes by Smith (2015), and that the crown clade is at least as old as the earliest Eocene. Recent studies based on genomes and multiple nuclear genes have provided younger, early Eocene divergence age estimates for crown Charadriiformes ( $\sim 57 \mathrm{Ma}$, Ericson et al., 2006; 56 Ma, Claramunt and Cracraft, 2015; 53.57 Ma, Smith, 2011; 53 Ma, Kimball et al., 2019; 48 Ma, Prum et al., 2015) that conflict with the Cretaceous divergence dates (ranging from 67.9 to $93.1 \mathrm{Ma}$ ) of the mitochondrial gene sequence and RAG1 nuclear gene sequence based studies reviewed by Smith (2011), (Paton et al., 2002, 2003; Pereira and Baker, 2006; Baker et al., 2007; Brown et al., 2007). Early Eocene and older ages for the crown clade estimated from combined morphological and molecular data (Smith and Clarke, 2015; Smith, 2015) are consistent with the analyses of the fossils assessed here. If correct, some recent divergence time estimates based on nuclear gene and genomic data have underestimated the divergence timing of this group as they have for crown Gruiformes (Musser et al., 2019), although caution needs to be taken in assessing this since the Eocene humeri are isolated, fragmented bones. Only four synapomorphies that were recovered as placing these taxa within crown Charadriiformes 
could be scored from these specimens: a fossa olecrani of the humerus with limited depth $(469(1))$, a proximally elongate supracondylaris dorsalis (470(2)), a deep and extensive fossa $m$. brachialis $(474(2))$, and a condylus dorsalis that is located distal to the distal terminus of the fossa $m$. brachialis (475(1), only present in IGM 100/1435). Both possible charadriiform skeletons, $N$. grandei and S. mikkelseni, are additionally missing their forelimbs, again suggesting that further studies need to assess the placement of these taxa to identify whether any of these fossils comprise robust calibration points for Charadriiformes.

Our placement of $N$. grandei and the results of our phylogenetic analyses more generally are consistent with a pattern similar to prior proposals for many major avian clades, with possible stem clade origin in Eurasia and rapid expansion into North America. The same pattern has currently been found within the fossil record of Gruiformes (Bertelli et al., 2011; Mayr, 2017; Musser et al., 2019); however, much work remains to be done and morphological data remain key to untangling the role that shifting distributions and ecologies played in avian evolution.

\section{ACCESSION NUMBERS}

ZooBank Identifier: urn:lsid:zoobank.org:pub:57238342-B0D24764-8F6C-79205EB14F1A

Genus: urn:lsid:zoobank.org:act:8B1CD8D4-6C0F-4535-B1B2C87286D6234B

Species: urn:lsid:zoobank.org:act:7E917BC1-DCC7-4046-B7FE14A9537E2F06

\section{DATA AVAILABILITY STATEMENT}

The datasets presented in this study can be found in online repositories. The names of the repository/repositories and accession number(s) can be found in the article/ Supplementary Material.

\section{REFERENCES}

Baker, A. J., Pereira, S. L., and Paton, T. A. (2007). A phylogenetic relationships and divergence times of Charadriiformes genera: multigene evidence for the Cretaceous origin of at least 14 clades of shorebirds. Biol. Lett. 3:2. doi: 10.1098/ rsbl.2006.0606

Baumel, J. J., and Witmer, L. M. (1993). “Osteologia," in Handbook of Avian Anatomy: Nomina Anatomica Avium, eds J. J. Baumel, A. S. King, J. E. Breazile, H. E. Evans, and J. C. Vanden Berge (Cambridge, NY: Publications of the Nuttall Ornithological Club), 45-132.

Bertelli, S., Chiappe, L. M., and Mayr, G. (2011). A new Messel rail from the early Eocene fur formation of Denmark (Aves, Messelornithidae). J. Syst. Palaeontol. 9:4. doi: 10.1080/14772019.2010.538730

Bertelli, S., Lindow, B. E. K., Dyke, G. J., and Chiappe, L. M. (2010). A wellpreserved 'charadriiform-like' fossil bird from the early Eocene Fur Formation of Denmark. J. Paleontol. 53:3. doi: 10.1111/j.1475-4983.2010.00950.x

Bertelli, S., Lindow, B. E. K., Dyke, G. J., and Mayr, G. (2013). Another charadriiform-like bird from the lower Eocene of Denmark. J. Paleontol. J. 47, 1282-1301. doi: 10.1134/S0031030114130024

\section{AUTHOR CONTRIBUTIONS}

GM performed the software and funding acquisition, collected most of the data, carried out the data curation, and wrote the original draft of the manuscript. Both authors performed the methodology, carried out the formal analyses and project administration, visualized and supervised the data, did the conceptualization, validated and investigated the data, carried out the resources, and wrote, reviewed, and edited the manuscript.

\section{FUNDING}

This project was supported by a National Science Foundation GRFP award (to GM, Grant number DGE-16-4486), an Ornithology Collections Study Grant from the American Museum of Natural History (to GM, 2019) and the Jackson School of Geosciences (GM and JC).

\section{ACKNOWLEDGMENTS}

We thank all of the staff of FMNH, especially Lance Grande, William Simpson, Adrienne Stroup, Shannon Hackett, John Bates, and Ben Marks, for specimen access and valuable discussion. We also thank April Neander for scanning the specimen and Matthew Colbert for aid in scan visualization and segmentation. We also thank Daniel Ksepka and Joel Cracraft for valuable discussion. GM would like to thank her recently deceased father, Guy G. Musser, for teaching her to fish and for his guidance throughout her life.

\section{SUPPLEMENTARY MATERIAL}

The Supplementary Material for this article can be found online at: https://www.frontiersin.org/articles/10.3389/fevo.2020. 559929/full\#supplementary-material

Brown, J. W., Payn, R. B., and Mindell, D. P. (2007). Nuclear DNA does not reconcile 'rocks' and 'clocks' in Neoaves: a comment on Ericson et al. Biol. Lett. 3:3. doi: 10.1098/rsbl.2006.0611

Buchheim, P. (1994). "Eocene fossil lake, green river formation, wyoming: a history of fluctuating salinity," in Sedimentology and Geochemistry of Modern and Ancient Saline Lakes, eds R. W. Renaut and W. M. Last (Broken Arrow, OK: SEPM Special Publication), 50. doi: 10.2110/pec.94. 50.0239

Claramunt, S., and Cracraft, J. L. (2015). A new time tree reveals Earth history's imprint on the evolution of modern birds. Sci. Adv. 1:11. doi: 10.1126/sciadv. 1501005

Clarke, J. A., Ksepka, D. T., Smith, N. A., and Norell, M. A. (2009). Combined phylogenetic analysis of a new North American fossil species confirms widespread Eocene distribution for stem rollers (Aves, Coracii). Zool. J. Linn. Soc. 157:3. doi: 10.1111/zoj. 12181

Cracraft, J. (1988). "The major clades of birds," in Phylogeny and Classification of the Tetrapods. Vol. 1. Amphibians, Reptiles, Birds, ed. J. Benton (Oxford: Systematics Association), 339-361. 
Cracraft, J. L., and Clarke, J. A. (2001). “The basal clades of modern birds," in New Perspectives on the Origin and Early Evolution of Birds, eds J. Gauthier and L. F. Gall (New Haven, CT: PeabodyMuseum of Natural History, Yale University), $143-156$.

del Hoyo, J., Elliott, A., Sargatal, J., Christie, D. A., and de Juana, E. (2020). Handbook of the Birds of the World Alive. Barcelona: Lynx Edicions.

Dunning, J. B. (2007). Handbook of Avian Body Masses, 2nd Edn. Boca Raton, FL: CRC Press.

Ericson, P. (1997). Systematic relationships of the Palaeogene family Presbyornithidae (Aves, Anseriformes). Zool. J. Linn. Soc. 121:4. doi: 10.1006/zjls.1997.0098

Ericson, P. (1999). New material of Juncitarsus (Phoenicopteriformes), with a guide for differentiating that genus from the Presbyornithidae (Anseriformes). Smithson. Contrib. Paleobiol. 89, 231-234.

Ericson, P. (2000). Systematic revision, skeletal anatomy, and paleoecology of the New World early Tertiary Presbyornithidae (Aves, Anseriformes). PaleoBios 20, $1-23$.

Ericson, P. G. P., Anderson, C. L., Britton, T., Elzanowski, A., Johansson, U. S., Källersjö, M., et al. (2006). Diversification of Neoaves: integration of molecular sequence data and fossils. Biol. Lett. 2:4. doi: 10.1098/rsbl.2006.0523

Ferreira, C. D., and Reginaldo, J. D. (2005). Osteologia craniana de Platalea ajaja (Linnaeus) (Aves, Ciconiiformes), comparada com outras espécies de Threskiornithidae. Rev. Bras. Zool. 22, 529-551. doi: 10.1590/s010181752005000300003

Field, D. J., Lynner, C., Brown, C., and Darroch, S. A. F. (2013). Skeletal correlates for body mass estimation in modern and fossil flying birds. PLoS One 8:e82000. doi: 10.1371 /journal.pone. 0082000

Grande, L. (1984). Paleontology of the green river formation, with a review of the fish fauna, 2nd ed. Geol. Survey Wyom. Bull. 63, 1-333.

Grande, L. (2013). The Lost World of Fossil Lake: Snapshots from Deep Time. Chicago: The University of Chicago Press.

Grande, L., and Buchheim, P. (1994). Paleontological and sedimentological variation in early Eocene Fossil Lake. Rocky Mount. Geol. 30:33-56. doi: 10. 2113/gsrocky.30.1.33

Hackett, S. J., Kimball, R. T., Reddy, S., Bowie, R. C. K., Braun, E. L., Braun, M. J., et al. (2008). A phylogenomic study of birds reveals their evolutionary history. Science 320:5884. doi: 10.1126/science.1157704

Hesse, A. (1988). Die Messelornithidae-eine neue Familie derKranichartigen (Aves: Gruiformes: Rhynocheti) aus dem Tertia $\ddot{r}$ Europas und Nordamerikas. J. Ornithol. 129, 83-95. doi: 10.1007/bf01641534

Hesse, A. (1990). Die Beschreibung der messelornithidae (Aves: Gruiformes: Rhynocheti) aus dem Alttertiär Europas und Nordamerikas. Cour. Forsch. Senckenberg. 128, 1-176.

Hesse, A. (1992). "A new species of Messelornis (Aves: Gruiformes: Messelornithidae) from the middle Eocene Green River Formation," in Contributions in Science: Papers in Avian Paleontotogy Honoring Pierce Brodkorb, ed. K. E. Campbell (Los Angeles, CA: Los Angeles County Museum of Natural History), 171-178.

Hood, S. C., Torres, C. R., Norell, M. A., and Clarke, J. A. (2019). New fossil birds from the earliest Eocene of Mongolia. Am. Mus. Novit. 2019:1. doi: 10.1206/ 3934.1

Hou, L., and Ericson, P. G. P. (2002). A middle Eocene shorebird from China. Condor 104:4. doi: 10.1093/condor/104.4.896

Hou, L. H. (1990). An Eocene bird from Songzi, Hubei province. Vertebrat. PalAsiatic. 28, 34-42.

Jarvis, E. D., Mirarab, S., Aberer, A. J., Li, B., Houde, P., Li, C., et al. (2014). Wholegenome analyses resolve early branches in the tree of life of modern birds. Science 346:6215. doi: 10.1126/science.1253451

Kimball, R. T., Oliveros, C. H., Wang, N., White, N. D., Barker, F. K., Field, D. J., et al. (2019). A phylogenomic supertree of birds. Diversity 11:7. doi: 10.3390/ d11070109

Ksepka, D. T., and Clarke, J. A. (2010a). New fossil mousebird (Aves: Coliiformes) with feather preservation provides insight into the ecological diversity of an Eocene North American avifauna. Zool. J. Linn. Soc. 160:4. doi: 10.1111/j.10963642.2009.00626.x

Ksepka, D. T., and Clarke, J. A. (2010b). Primobucco mcgrewi (Aves: Coracii) from the Eocene Green River Formation: new anatomical data from the earliest constrained record of stem rollers. J. Vertebr. Paleontol. 30:1. doi: 10.1080/ 02724630903412414

Ksepka, D. T., and Clarke, J. A. (2012). A new stem parrot from the Green River Formation and the complex evolution of the grasping foot in PanPsittaciformes. J. Vertebr. Paleontol. 32:2. doi: 10.1080/02724634.2012.641704

Ksepka, D. T., Clarke, J. A., and Grande, L. (2011). Stem parrots (Aves, Halcyornithidae) from the Green river formation and a combined phylogeny of pan-psittaciformes. J. Paleontol. 85:5. doi: 10.1666/10-108.1

Ksepka, D. T., Grande, L., and Mayr, M. (2019). Oldest Finch-beaked birds reveal parallel ecological radiations in the earliest evolution of Passerines. Curr. Biol. 29:4. doi: 10.1016/j.cub.2018.12.040

Linnaeus, C. (1758). Systema Naturae per Regna Tria Naturae, Secundum Classes, Ordines, Genera, Species, Cum Characteribus, Differentiis, Synonymis, Locis (Photographic Facsimile). London: British Museum of Natural History, doi: 10.5962/bhl.title.542

Livezey, B. C. (1998). A phylogenetic analysis of the Gruiformes (Aves) based on morphological characters, with an emphasis on the rails (Rallidae). Philos. Trans. R. Soc. Lond. B Biol. Sci. 353, 2077-2151. doi: 10.1098/rstb.1998.0353

Livezey, B. C. (2009). Phylogenetics of modern shorebirds (Charadriiformes) based on phenotypic evidence: characterization. Bull. Carnegie Mus. Nat. Hist. 40, 1-95. doi: 10.2992/013.040.0101

Livezey, B. C. (2010). Phylogenetics of modern shorebirds (Charadriiformes) based on phenotypic evidence: analysis and discussion. Zool. J. Linn. Soc. 160, 567-618. doi: 10.1111/j.1096-3642.2010.00635.x

Livezey, B. C., and Zusi, R. L. (2006). Higher-order phylogeny of modern birds (Theropoda, Aves: Neornithes) based on comparative anatomy (I. Methods and characters). Bull. Carnegie Mus. Nat. Hist. 37, 1-544. doi: 10.1111/j.1096-3642. 2006.00293.x

Livezey, B. C., and Zusi, R. L. (2007). Higher-order phylogeny of modern birds (Theropoda, Aves: Neornithes) based on comparative anatomy (II. Analysis and discussion). Zool. J. Linn. Soc. 149:1.

Mayr, G. (2000a). A remarkable new 'gruiform' bird from the Middle Eocene of Messel (Hessen, Germany). Paläontol. Z. 74, 187-194. doi: 10.1007/ BF02987960

Mayr, G. (2000b). Charadriiform birds from the early Oligocene of Cereste (France) and the middle Eocene of Messel (Hessen, Germany). Geobios 33, 625-636. doi: 10.1016/s0016-6995(00)80034-0

Mayr, G. (2002). A new specimen of Salmila robusta (Aves: Gruiformes: Salmilidae n. fam.) from the Middle Eocene of Messel. Paläontol. Z. 76, 305-316. doi: 10.1007/BF02989866

Mayr, G. (2004). The phylogenetic relationships of the early Tertiary Primoscenidae and Sylphornithidae and the sister taxon of crown group piciform birds. J. Ornithol. 145, 188-198.

Mayr, G. (2008). Avian higher-level phylogeny: well-supported clades and what we can learn from a phylogenetic analysis of 2954 morphological characters. J. Zool. Syst. Evol. Res. 46, 63-72.

Mayr, G. (2009). Paleogene Fossil Birds. Berlin: Springer.

Mayr, G. (2011a). On the osteology and phylogenetic affinities of Morsoravis sedilis (Aves) from the early Eocene Fur Formation of Denmark. Bull. Geol. Soc. Denmark. 59, 23-35.

Mayr, G. (2011b). The phylogeny of charadriiform birds (shorebirds and allies) reassessing the conflict between morphology and molecules. Zool. J. Linn. Soc. 161, 916-934. doi: 10.1111/j.1096-3642.2010.00654.x

Mayr, G. (2013). Parvigruidae (Aves, core Gruiformes) from the early Oligocene of Belgium. Paleodivers. Paleoenviron. 93, 77-89. doi: 10.1007/s12549-012-0083-7

Mayr, G. (2016). The world's smallest owl, the earliest unambiguous charadriiform bird, and other avian remains from the early Eocene Nanjemoy Formation of Virginia (USA). Paläontol. Z. 90, 747-763. doi: 10.1007/s12542-0160330-8

Mayr, G. (2017). Avian Evolution: The Fossil Record of Birds and Its Paleobiological Significance. West Sussex: John Wiley and Sons Ltd.

Mayr, G., and Clarke, J. A. (2003). The deep divergences of neornithine birds: a phylogenetic analysis of morphological characters. Cladistics 19, 527-553. doi: 10.1111/j.1096-0031.2003.tb00387.x

Musser, G., Ksepka, D. T., and Field, D. J. (2019). New material of paleoceneeocene Pellornis (Aves: Gruiformes) clarifies the pattern and timing of the extant gruiform radiation. Diversity 11:102. doi: 10.3390/d11070102 
Musser, G. M., and Cracraft, J. (2019). A new morphological dataset reveals a novel relationship for the adzebills of New Zealand (Aptornis) and provides a foundation for total evidence neoavian phylogenetics. Am. Mus. Novit. 2019, 1-70. doi: 10.1206/3927.1

Nesbitt, S. J., and Clarke, J. A. (2016). The anatomy and taxonomy of the exquisitely preserved green river formation (Early Eocene) Lithornithids (Aves) and the relationships of lithornithidae. Bull. Am. Mus. Nat. Hist. 2016, 1-91. doi: 10. 1206/0003-0090-406.1.1

O'Leary, M. A., and Kaufman, S. G. (2012). MorphoBank 3.0: Web Application for Morphological Phylogenetics and Taxonomy. Available online at: https:// morphobank.org (accessed March 12, 2019).

Olson, S. L. (1976). A jacana from the Pliocene of Florida (Aves: Jacanidae). Proc. Biol. Soc. Wash. 89, 259-264.

Olson, S. L., and Matsuoka, H. (2005). New specimens of the early Eocene frigatebird Limnofregata (Pelecaniformes: Fregatidae), with the description of a new species. Zootaxa 1046, 1-15. doi: 10.11646/zootaxa.1046.1.1

Paton, T. A., Baker, A. J., Groth, J. G., and Barrowclough, G. F. (2003). RAG-1 sequences resolve phylogenetic relationships within charadriiform birds. Mol. Phylogenet. Evol. 29:2. doi: 10.1016/S1055-7903(03)00098-8

Paton, T. A., Haddrath, O., and Baker, A. J. (2002). Complete mitochondrial DNA genome sequences show that modern birds are not descended from transitional shorebirds. Proc. Biol. Sci. 269, 839-846. doi: 10.1098/rspb.2002.1961

Pedersen, G. K., and Surlyk, F. (1983). The Fur Formation, a late Paleocene ash-bearing diatomite from northern Denmark. Bull. Geol. Soc. Denmark 32, 43-65.

Pereira, S. L., and Baker, A. J. (2006). A mitogenomic timescale for birds detects variable phylogenetic rates of molecular evolution and refutes the standard molecular clock. Mol. Biol. Evol. 23:9. doi: 10.1093/molbev/msl038

Prum, R. O., Berv, J. S., Dornburg, A., Field, D. J., Townsend, J. P., Lemmon, E. M., et al. (2015). A comprehensive phylogeny of birds (Aves) using targeted next-generation DNA sequencing. Nature 526, 569-573. doi: 10.1038/nature 15697

Pycraft, W. P. (1900). On the morphology and phylogeny of the Palaeognathae (Ratitae and Crypturi) and Neognathae (Carinatae). Trans. Zool. Soc. Lond. 15, 149-290. doi: 10.1111/j.1096-3642.1900.tb00023.x

Rasmussen, D. T., Olson, S. L., and Simons, E. L. (1987). Fossil Birds from the Oligocene Jebel Qatrani Formation, Fayum Province, Egypt. Washington, DC: Smithsonian Institution, 7-8.

Reddy, S., Kimball, R. T., Pandey, A., Hosner, P. A., Braun, M. J., Hackett, S. J., et al. (2017). Why do phylogenomic data sets yield conflicting trees? Data type influences the avian tree of life more than taxon sampling. Syst. Biol. 66:5. doi: $10.1093 /$ sysbio/syx041

Shoshoni Language Project (2018). Shoshoni Dictionary. Available online at: https://shoshoniproject.utah.edu/language-materials/shoshoni-dictionary/ dictionary.php (accessed August 6, 2020).

Sibley, C. G., Ahlquist, J. E., and Monroe, B. L. Jr. (1988). A classification of the living birds of the world based on DNA-DNA hybridization studies. Auk 105, 409-423. doi: 10.1093/auk/105.3.409

Smith, M. E., Chamberlain, K. R., Singer, B. S., and Carroll, A. R. (2010). Eocene clocks agree: coeval 40Ar/39Ar, U-Pb, and astronomical ages from the Green River Formation. J. Geol. 38:6. doi: 10.1130/G30630.1
Smith, N. A. (2011). Systematics and Evolution of Extinct and Extant PanAlcidae (Aves, Charadriiformes): Combined Phylogenetic Analyses, Divergence Estimation, and Paleoclimatic Interactions. Ph. D. Dissertation, The University of Texas at Austin, Austin, TX.

Smith, N. A. (2013). A new species of Threskiornithidae-like bird (Aves, Ciconiiformes) from the Green river formation (Eocene) of wyoming. J. Vertebr. Paleontol. 33:2. doi: 10.1080/02724634.2012.722898

Smith, N. A. (2015). Sixteen vetted fossil calibrations for divergence dating of Charadriiformes (Aves, Neognathae). Palaeontol. Electron. 18.1.4FC, 1-18. doi: $10.26879 / 410$

Smith, N. A., and Clarke, J. A. (2015). Systematics and evolution of the Pan-Alcidae (Aves, Charadriiformes). J. Avian Biol. 45, 001-016. doi: 10.1111/jav.00487

Storer, R. W. (1971). "Adaptive radiation of birds," in Avian Biology, Vol. 1, eds D. S. Farner and J. R. King (New York: Academic Press), 149-188.

Strauch, J. G. (1978). The phylogeny of the Charadriiformes (Aves): a new estimate using the method of character compatibility analysis. Trans. Zool. Soc. Lond. 34, 263-345. doi: 10.1111/j.1096-3642.1978.tb00375.x

Swofford, D. L. (2002). PAUP* Phylogenetic Analysis Using Parsimony (*and Other Methods). Version 4.0a164 (X86). Sunderland, MA: Sinauer Associates.

Thomas, A. L. R. (1993). On the aerodynamics of birds' tails. Philos. Trans. R. Soc. B. 340:1294. doi: 10.1098/rstb.1993.0079

Thomas, A. L. R., and Balmford, A. (1995). How natural selection shapes birds'. Tails. Am. Nat. 146:6. doi: 10.1086/285828

van Tuinen, M., and Hedges, S. B. (2001). Calibration of avian molecular clocks. Mol. Biol. Evol. 18:2. doi: 10.1093/oxfordjournals.molbev.a003794

Wang, M., Mayr, G., Zhang, J., and Zhou, Z. (2012). Two new skeletons of the enigmatic, rail-like avian taxon Songzia Hou, 1990 (Songziidae) from the early Eocene of China. Alcheringa Aust. J. Paleontol. 36:4. doi: 10.1080/03115518. 2012.673302

Weidig, I. (2010). New birds from the lower eocene green river formation, North America," in Proceedings of the VII International meeting of the society of avian paleontology and evolution, eds W. E. Boles, T. H. Worthy. Rec. Aust. Mus. 62:1. doi: 10.3853/j.0067-1975.62.2010.1544

Zeffer, A., Christoffer, J. L., and Marmebro, A. (2003). Functional correlation between habitat use and leg morphology in birds (Aves). Biol. J. Linn. Soc. 79, 461-484. doi: 10.1046/j.1095-8312.2003.00200.x

Zusi, R. L. (1984). A functional and evolutionary analysis of rhynchokinesis in birds. Smithson. Contrib. Zool. 395, 1-40. doi: 10.5479/si.00810282.395

Conflict of Interest: The authors declare that the research was conducted in the absence of any commercial or financial relationships that could be construed as a potential conflict of interest.

The handling editor declared a past co-authorship with the authors.

Copyright (C) 2020 Musser and Clarke. This is an open-access article distributed under the terms of the Creative Commons Attribution License (CC BY). The use, distribution or reproduction in other forums is permitted, provided the original author(s) and the copyright owner(s) are credited and that the original publication in this journal is cited, in accordance with accepted academic practice. No use, distribution or reproduction is permitted which does not comply with these terms. 